\title{
The use of virtual characters to assess and train non-verbal communication in high-functioning autism
}

\author{
Alexandra Livia Georgescu ${ }^{1}$, Bojana Kuzmanovic ${ }^{1,2}$, Daniel Roth ${ }^{3}$, Gary Bente ${ }^{3}$ and Kai Vogeley ${ }^{1,4}$ \\ ${ }^{1}$ Department of Psychiatry and Psychotherapy, University Hospital Cologne, Cologne, Germany \\ ${ }^{2}$ Ethics in the Neurosciences (INM-8), Institute of Neuroscience and Medicine, Research Center Juelich, Juelich, Germany \\ ${ }^{3}$ Department of Psychology, University of Cologne, Cologne, Germany \\ ${ }^{4}$ Cognitive Neuroscience (INM-3), Institute of Neuroscience and Medicine, Research Center Juelich, Juelich, Germany
}

Edited by:

Ouriel Grynszpan, Université Pierre et Marie Curie, France

Reviewed by:

Antonia Hamilton, The University of Nottingham, UK

Michal Hochhauser, University of

Haifa, Israel

*Correspondence:

Alexandra Livia Georgescu,

Department of Psychiatry and

Psychotherapy, University Hospital

Cologne, Kerpener Strasse 62,

Cologne 50924, Germany

e-mail: alexandra.georgescu@

uk-koeln.de
High-functioning autism (HFA) is a neurodevelopmental disorder, which is characterized by life-long socio-communicative impairments on the one hand and preserved verbal and general learning and memory abilities on the other. One of the areas where particular difficulties are observable is the understanding of non-verbal communication cues. Thus, investigating the underlying psychological processes and neural mechanisms of non-verbal communication in HFA allows a better understanding of this disorder, and potentially enables the development of more efficient forms of psychotherapy and trainings. However, the research on non-verbal information processing in HFA faces several methodological challenges. The use of virtual characters (VCs) helps to overcome such challenges by enabling an ecologically valid experience of social presence, and by providing an experimental platform that can be systematically and fully controlled. To make this field of research accessible to a broader audience, we elaborate in the first part of the review the validity of using VCs in non-verbal behavior research on HFA, and we review current relevant paradigms and findings from social-cognitive neuroscience. In the second part, we argue for the use of VCs as either agents or avatars in the context of "transformed social interactions." This allows for the implementation of real-time social interaction in virtual experimental settings, which represents a more sensitive measure of socio-communicative impairments in HFA. Finally, we argue that VCs and environments are a valuable assistive, educational and therapeutic tool for HFA.

Keywords: high-functioning autism, non-verbal behavior, social interaction, virtual reality, virtual characters, social gaze

\section{NON-VERBAL COMMUNICATION AND HIGH-FUNCTIONING AUTISM \\ NON-VERBAL BEHAVIOR AND SOCIAL COGNITION}

Non-verbal communication constitutes an essential aspect of social cognition. Indeed, non-verbal cues are known to influence person perception and construal processes early during social encounters (Willis and Todorov, 2006) and a large proportion of social meaning is substantially informed by non-verbal cues (Argyle, 1988; Burgoon, 1994). Thus, the investigation of the behavioral and neural correlates of non-verbal behavior processing can deliver valuable insights into social cognition and human communication.

Behavioral research has long been investigating the perception and evaluation of facial or bodily cues (i.e., decoding of emotions and intentions). More recently, the field of social and affective neuroscience has also started investigating the underlying neural

Abbreviations: AON, action observation network; ASD, autism spectrum disorder; CVE, collaborative virtual environment (aka shared virtual environment); DVE, desktop virtual environment; fMRI, functional magnetic resonance imaging; HFA, high-functioning autism; IVE, immersive virtual environment; SNN, social neural network; SVE, single-user virtual environment; TSI, transformed social interaction; VC, virtual characters; VE, virtual environment; VR, virtual reality. mechanisms associated with the social processing of facial and bodily non-verbal cues (in terms of mental state attribution, Gallagher and Frith, 2003; De Gelder and Hortensius, 2014), and also those involved in perceiving meaningful intransitive actions (i.e., non-object directed), be they mimed, expressive, or symbolic (e.g., Gallagher and Frith, 2004; Grèzes et al., 2007; Villarreal et al., 2008). Neurally, this processing is traceable to two main networks in the human brain: the action observation network (AON), associated with human movement perception, and the social neural network (SNN), involved in social-cognitive processing (e.g., Van Overwalle and Baetens, 2009).

\section{HIGH-FUNCTIONING AUTISM AND NON-VERBAL BEHAVIOR}

Autism spectrum disorders (ASD) are characterized by impairments in communication and reciprocal interaction (World Health Organization, 1993). Socio-communicative deficits in high-functioning autism (HFA) manifest themselves in problems with spontaneously producing, interpreting, and responding to non-verbal cues. More specifically, on the perception side, the intrinsic value and salience of non-verbal cues are reduced in individuals with HFA. They do not spontaneously attend to social information, and are thus less able to intuitively interact in social 
contexts (Klin et al., 2003). When confronted with non-verbal signals, such as eye gaze, facial expressions, or gestures; individuals with HFA have shown atypical detection (Senju et al., 2005, 2008; Dratsch et al., 2013) and interpretation of such cues (BaronCohen, 1995; Baron-Cohen et al., 1997; Uljarevic and Hamilton, 2013) and have difficulties in integrating them for the purpose of an adequate impression formation of others (Kuzmanovic et al., 2011). Generally, they seem to be less affected by them when processing a task, as compared with typically developed control persons (Schwartz et al., 2010; Schilbach et al., 2012), and/or they seem to use atypical strategies for social processing (e.g., Kuzmanovic et al., 2014; Walsh et al., 2014). Furthermore, neuroimaging studies have shown that the SNN, which is involved in conscious mental inference and evaluation of social stimuli (Gallagher and Frith, 2003; Frith, 2007; Van Overwalle and Baetens, 2009), shows a diminished response to the processing of non-verbal social information in HFA (Baron-Cohen et al., 1999; Critchley et al., 2000; Piggot et al., 2004; Pelphrey et al., 2005; Ashwin et al., 2007; Pitskel et al., 2011; Redcay et al., 2012; von dem Hagen et al., 2013; Georgescu et al., 2013; Kuzmanovic et al., 2014).

Thus, non-verbal information may influence social perception, as well as affective and inferential processing, all of which have been demonstrated to be impaired in HFA. In addition, non-verbal behavior exhibits specifically high levels of complexity that are closely related to intuitive cognitive and affective processing. For this reason, investigating non-verbal behavior processing in HFA not only helps to understand (1) social cognition and its underlying neural mechanisms but also (2) the specific cognitive style characteristic of HFA. These insights, in turn, are most valuable for improving supportive therapy and training options, which may improve the lives of affected individuals and their families.

Nevertheless, the investigation of non-verbal behavior faces several basic methodological challenges, which will be elaborated in the next section. Virtual characters (VCs) are introduced as a means to overcome such methodological issues and various experimental implementations are discussed. Finally, we will consider how these implementations have been or could be used in the future for research and training with individuals with HFA.

\section{VIRTUAL CHARACTERS AS A TOOL FOR NON-VERBAL BEHAVIOR RESEARCH BASIC METHODOLOGICAL PROBLEMS IN NON-VERBAL BEHAVIOR RESEARCH}

In contrast to verbal communication, non-verbal cues cannot be readily translated into distinct meanings (Krämer, 2008). In fact, non-verbal behavior is characterized by (a) high dimensional complexity and (b) high processual complexity (Krämer, 2008; Vogeley and Bente, 2010). Dimensional complexity relates to the fact that non-verbal signals are highly context dependent and comprise a simultaneous multichannel activity (Poyatos, 1983). The interpretation of a single non-verbal cue depends on which other verbal, non-verbal, and situational cues precede, co-occur with, or follow it (e.g., Grammer, 1990; Chovil, 1991). Moreover, processual complexity implies that meaningful information is conveyed by dynamic aspects of facial expressions and movements of the head or body, and that subtle spatiotemporal characteristics of perceived behavior can affect the way that non-verbal information is processed (e.g., Birdwhistell, 1970; Grammer et al., 1988, 1999; Krumhuber and Kappas, 2005; Krumhuber et al., 2007; Provost et al., 2008). Therefore, Burgoon et al. (1989) (p. 23) argue for the use of dynamic non-verbal stimuli and suggest that "we need to understand non-verbal communication as an ongoing, dynamic process rather than just a static snapshot of cues or final outcomes at one moment of time."

Some researchers have used dynamic non-verbal stimuli either by using so-called "thin slices" of people's behavioral streams (i.e., brief excerpts of behavior, less than $5 \mathrm{~min}$ in length; Ambady and Rosenthal, 1992), or by instructing confederates or actors to produce or vary particular aspects of their non-verbal behavior. This approach, however, has its disadvantages due to the fact that implicit movement qualities are both produced and perceived automatically and outside awareness, hence making them difficult to capture and/or control experimentally (Choi et al., 2005). Therefore, a large amount of research to date has investigated non-verbal cues using only static photographs or pictures of, for instance, specific gestures or emotional faces and bodies.

In addition, when using neuroimaging techniques to investigate non-verbal behavior processing, a set of unique challenges with respect to ecological validity emerges. David (2012) states that participants are restricted in the movements they can make in order to prevent artifacts in the recording of neural data. Therefore, neuroimaging paradigms are rather limited in terms of how much they allow participants to engage with a social stimulus. Furthermore, increasing ecological validity involves increasing complexity of the stimulus material and/or task demands, which raise the question concerning what a "neural correlate" actually really reflects (David, 2012). Therefore, oftentimes for experiments, social scripts and stimuli have to be reduced and presented repeatedly, in order to increase statistical power, yet then they also lack ecological validity and may lead to habituation and/or expectancy effects.

To sum up, the investigation of the processing of non-verbal behavior meets several basic methodological challenges, some inherent in the nature of the stimulus (i.e., experimental control) and others caused by technical restrictions (i.e., ecological validity).

\section{VIRTUAL CHARACTERS OFFER A GOOD COMPROMISE BETWEEN EXPERIMENTAL CONTROL AND ECOLOGICAL VALIDITY}

The abovementioned challenges can be overcome by using anthropomorphic VCs. These are artificial characters, which have realistic human features, can be either static or dynamic and can either be animated by using key framing or motion-capturing techniques. Moreover, VCs are a medium through which virtual interaction partners can be expressed. In this line, research distinguishes between two possible virtual representations of human beings in an interacting context, which differ in terms of their level of agency (Bailenson and Blascovich, 2004; Bailenson et al., 2006; von der Pütten et al., 2010b): (1) agents (i.e., a digital model of a person, which is driven by a computer algorithm) and (2) avatars (i.e., a digital model of a person, which is controlled by a real human in real time). VCs have the advantage of realistic behavior capabilities on the one hand, and systematic manipulability on the other, hence allowing the simultaneous increase of both experimental control and ecological validity (Vogeley and Bente, 
2010; Bohil et al., 2011). Moreover, they provide the option to control and investigate body motion independently from body shape, a methodological advantage termed as "plasticity" by Bente and Krämer (2011). This possibility of independently masking or transforming aspects of both appearance and behavior is essential in order to disentangle top-down effects of appearance from bottom-up effects of behavior (Bente et al., 2008).

The most important prerequisite for using VCs for non-verbal behavior research is that they are veridical and convincing and that they are able to evoke impressions, attributions, and reactions in an observer that are comparable to those evoked by real human beings (Krämer, 2008; Vogeley and Bente, 2010). Indeed, the validity of VCs in non-verbal behavior research has been amply demonstrated in both behavioral and neuroimaging studies, and there is consistent evidence that VCs are perceived comparably to real human beings. For example, a series of studies have shown that person perception ratings based on the non-verbal behavior of videotaped human beings do not differ significantly from those based on the identical movements performed by VCs (Bente et al., 2001). Moreover, virtual emotional facial and bodily expressions are recognized as accurately as natural ones (Dyck et al., 2008; McDonnell et al., 2008), and recent functional neuroimaging research demonstrated that facial animations of emotional virtual faces also evoke brain responses comparable to those evoked by real human faces, specifically in the amygdala (Moser et al., 2007), a region robustly associated with social processing (Adolphs et al., 1998).

\section{METHODOLOGICAL IMPLEMENTATIONS AND SETUPS FOR THE USE OF VIRTUAL CHARACTERS}

Virtual characters can be used within a variety of virtual reality (VR) systems, which can differ in terms of their immersive potential. Immersion refers to the degree of sensory stimulation through the system on the one hand and the sensitivity of the system to motor inputs, on the other (Biocca et al., 2003). Thus, the level of immersion of a VR system is determined by the number of sensory and motor channels connected to the virtual environment (VE) (Biocca et al., 2003). For instance, desktop virtual environments (DVEs) typically involve a user viewing a VE through a computer screen (Bente and Krämer, 2011). While a participant can interact with the environment, using common input devices, such as keyboard, mouse, joystick, or touchscreen, the interaction does not include a high degree of immersion. Some examples for the use of DVEs would be the interaction within online communities like "Second Life" or various desktop-based training programs. Nevertheless, for research investigating not just the perception but also the production side of non-verbal behavior, there is an important consideration to be made: classic DVE setups often require a conscious decision by the user to launch the non-verbal cue via discrete input options, such as clicking a button or hitting a key (Bente and Krämer, 2011). Thus, the sender of a non-verbal message would be more self-aware, as they would have to consciously choose what to display and when to do it. Furthermore, the number of non-verbal signals produced is restricted as cognitive resources of the sender are limited (Bente and Krämer, 2011). Nevertheless, even though they lack peripheral vision, DVEs can increase their immersive potential, by making use of stereoscopic monitors and/or head tracking (e.g., Fish Tank VR, Ware et al., 1993). Another example, would be the virtual communication environment [VCE, by Bente and Krämer (2011), see also the desktop platform illustrated in Figure 1], which is a DVE paradigm that conveys in real time a wide range of non-verbal cues via eye and motion tracking.

The so-called immersive virtual environments (IVEs) typically have a higher immersion potential, compared to classic DVEs, which can be achieved for instance by including continuous realtime tracking of a user's movements with high degrees of freedom and/or by engaging peripheral in addition to central vision (Bente and Krämer, 2011). Such systems are better at capturing and transmitting a broader range of behavior and allowing for a spontaneous and subconscious usage of non-verbal cues (Bente and Krämer, 2011). IVEs may make use of different display and tracking solutions. For instance, curved screen projections, such as Powerwalls or Tiled Walls (e.g., HEyeWall; Santos et al., 2007) use a combination of multiple projectors or LCD panels to increase the overall display size and resolution and display monoscopic or stereoscopic content. Some systems are equipped with a head mounted display (HMD, a visual display worn as a type of helmet) and are directly tracking movements of the user's head and/or body to duplicate them within the VE (Bohil et al., 2011). Another type of IVE refers to open display systems, where the user is inside a room or sphere, the surface of which is a seamless display system such as CAVEs (Cruz-Neira et al., 1993) or fulldomes (Bohil et al., 2011). To increase immersiveness, all these setups may use devices to track locomotion (location trackers), hand movements (data gloves or 3D mice), and body motion (motion capture). It has to be noted that, due to end-to-end time lags (between users actions and the correspondent display changes) such immersive technologies can cause "virtual reality induced symptoms and effects" (VRISE, Sharples et al., 2008, previously also referred to as "cyber-sickness," LaViola, 2000). This issue has to be considered when designing experiments in IVEs.

Whether DVEs or IVEs are used, and which level of immersion is adopted for research purposes, usually depends on the research question, as well as on the budget and accessibility of the technology.

\section{RECENT DEVELOPMENTS IN BEHAVIORAL PARADIGMS USING VIRTUAL CHARACTERS AS REAL-TIME INTERACTION PARTNERS}

Most behavioral and neuroimaging studies on non-verbal behavior processing using VCs have used DVEs and observational paradigms and have focused mostly on the perception side of social cognition. In such paradigms, a participant merely observes and evaluates non-verbal cues performed by a virtual other on a screen, without being involved in an interaction with them (e.g., Schilbach et al., 2006; Kuzmanovic et al., 2009, 2012). De Gelder and Hortensius (2014) (p. 160) explain that in observational paradigms, which are also called "offline" paradigms (Pfeiffer et al., 2013a; Schilbach et al., 2013; Schilbach, 2014), the "person observed is not influenced by the way his/her actions are perceived by others. On the other hand, the observer does not get any feedback or insight from his/her correct perception; neither does he/she suffer the consequences of misperception." In the same line, Patterson (1994) highlights that social interaction consists of both person perception and behavior production simultaneously. Thus, 


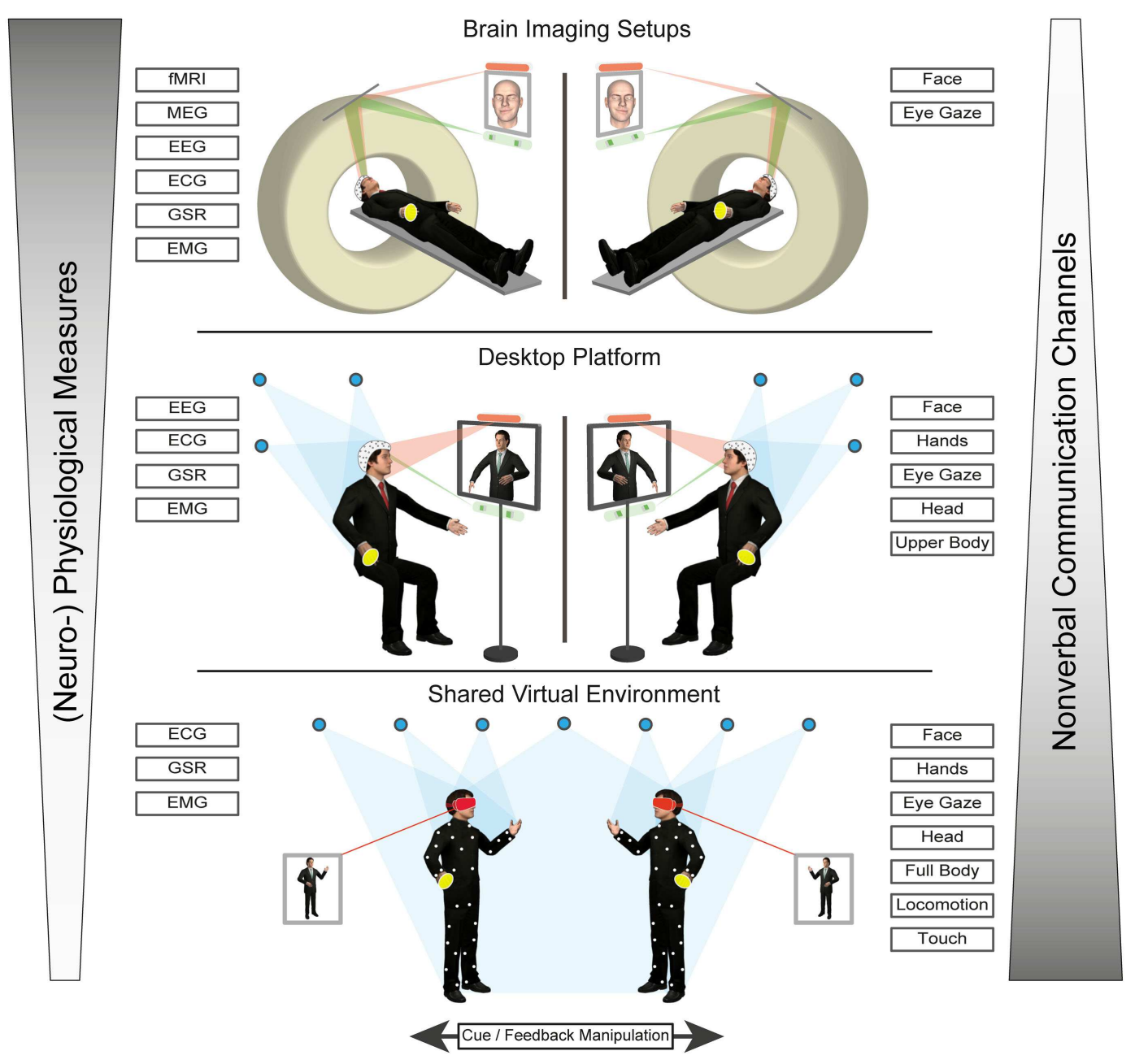

FIGURE 1 | Illustration of a prototype of a multilayer avatar platform to study production and perception of non-verbal cues in "online" social interaction paradigms. It shows that increasing ecological realism and communication bandwidth measurement (comprising eyes, face, gaze, movement and even touch) comes at the cost of measurement channels (such as sensors and devices) and that a tradeoff has to be achieved, based on the research question of interest. there is growing consent that observational paradigms alone are insufficient for a comprehensive understanding of the neural mechanisms of social cognition, and researchers have recently been arguing for a paradigm shift toward "online," interactive experimental designs [Hari and Kujala, 2009; Dumas, 2011; Konvalinka and Roepstorff, 2012; Pfeiffer et al., 2013a; Schilbach et al., 2013; Schilbach, 2014; but see also Przyrembel et al. (2012) for a more cautious review highlighting current limitations from a philosophical, psychological, and neuroscientific perspective].

Confirmation for the validity of VCs for "online," interactive paradigms comes from VR research, where agents have been observed to evoke comparable social effects and behaviors as during the interaction with a real human (e.g., Sproull et al., 1996; Nass and Moon, 2000; Hoyt et al., 2003; Park and Catrambone, 2007). Moreover, VR research has repeatedly confirmed that social interactions in VEs are governed by the same social norms as social interactions in the real world, and that social norms relating to gender, interpersonal distance, approach behavior, and eye gaze can be transferred to VEs (Bailenson et al., 2001; Garau et al., 2005; Yee et al., 2007). However, one of the shortcomings of "online" social interaction paradigms is the fact that, once an experimental variation has been introduced, it most likely develops its own dynamics (Bente and Krämer, 2011).

One of the most promising approaches to study non-verbal communication in "online" social interactions is the "transformed social interaction" (TSI) approach (Bailenson et al., 2004; Krämer, 2008), which builds upon the previously mentioned "plasticity" advantage of VCs (Bente et al., 2008). In this approach, motion is captured and rendered on an avatar. Not only the appearance of the VC (containing information for instance on sex, identity, ethnicity, or attractiveness), but also their non-verbal behavior can be manipulated, by blending particular channels (via static filters), or by modifying specific non-verbal cues (via dynamic filters, e.g., head movement activity can be altered using specific algorithms) (Bente and Krämer, 2011). By doing this in a systematic manner, it can be determined which aspects of non-verbal 
behavior are necessary and/or most efficient with regard to various social contexts. This makes it possible to analyze how manipulations of appearance and/or behavior of one agent or a dyad affect the experience and the course of social interactions. Blascovich et al. (2002) (p.121) summarize the benefits of this approach by stating "investigators can take apart the very fabric of social interaction using immersive virtual environment technology (IVET), disabling or altering the operation of its components, and thereby reverse engineering social interaction. With this approach, social psychologists could systematically determine the critical aspects of successful and unsuccessful social interactions, at least within specified domains and interaction tasks."

The TSI approach has been used to study the effects of experimentally manipulated gaze behavior in ongoing interactions. Bente et al. (2007a,b), used eye tracking and motion capture to control two avatars representing two interactants during an open conversation. While gestures and movements were conveyed in real time, the display of gaze direction was manipulated. The authors could show that longer periods of directed gaze fostered the positive evaluation of the partner. The study demonstrated how experimental control of non-verbal cues can be implemented within a rich and fluent social interaction. Other studies using gaze-contingent eye-tracking paradigms have been developed to investigate how social gaze is used to coordinate attention between a participant and an agent (Schilbach et al., 2010; Wilms et al., 2010; Pfeiffer et al., 2011). Finally, paradigms investigating the social effects of mimicry during social interactions with VCs have been developed as well (Bailenson and Yee, 2005, 2007).

To conclude, the "online" social interaction approach in nonverbal behavior research asks for the analysis of behavioral as well as physiological and neural patterns emerging across agents during social interactions. The specific advantages of using VCs in this type of research have been demonstrated for rather simple and restricted non-verbal cue systems, such as social gaze. Nevertheless, this approach can be easily extended to higher complexity levels in non-verbal behavior (see also "shared virtual environment" in Figure 1).

\section{RECENT DEVELOPMENTS IN NEUROIMAGING PARADIGMS USING VIRTUAL CHARACTERS AS REAL-TIME INTERACTION PARTNERS}

Using VR in neuroimaging paradigms [for instance functional magnetic resonance imaging, functional magnetic resonance imaging (fMRI) paradigms] increases the potential of standard fMRI paradigms, where the volunteer usually has the passive role of watching a simple stimulus without any interaction. In this line, De Gelder and Hortensius (2014) (p. 160) argue that VR provides the field of social-cognitive neuroscience with a powerful tool to study affective loops created by "online" interactions "in settings where real-life manipulation is not possible, too expensive or unethical."

In neuroimaging studies, however, despite the technical advancement of the VR and motion capture technologies, the possibilities of studying non-verbal communication in social interaction are limited. First, social scripts would have to be systematically manipulated, reduced, and presented repeatedly, in order to increase statistical power. Moreover, not only need the experimenters ensure that the motion tracking systems are compatible with the available neuroimaging techniques (e.g., MR-compatible for fMRI experiments), but participants are also restricted in their movements to prevent causing artifacts during neural data acquisition. Indeed, research is being done on developing VR platforms that are compatible with magnetic resonance imaging systems (e.g., Baumann et al., 2003; Mraz et al., 2003; see also Figure 1).

There are, however, several ways to overcome this problem. One way would be to create VEs, where the visual embodiment of the participants and hence their means of interaction with the virtual world and virtual other is controlled via some limited input information in the scanner environment. Although far from ideal (since it involves awareness and explicit production of non-verbal behavior), this approach presupposes that a virtual avatar can be controlled by using button presses or a joystick. In this line, Baumann et al. (2003) have developed a VR system of integrated software and hardware for neurobehavioral and clinical studies for fMRI studies. The authors propose a VR system, which includes a joystick for navigation, a touchpad, and an optional data glove with an attached motion tracker. Furthermore, the setup enables the measurement of physiological data (respiration, heart rate, blood volume pulsatility, and skin conductance response), and the system provides synchronization of the VR simulation with the physiological recordings and the functional MR images (see also "brain imaging setups" in Figure 1).

Another possibility of using VR in the fMRI context would be to investigate a form of minimal social interaction, which would, by definition, only require minimal non-verbal input but would enable the study of social interactions based on gaze behavior in real time. In this line, social gaze paradigms offer a good solution (Schilbach et al., 2010; Wilms et al., 2010; Pfeiffer et al., 2011, 2013b). Recent methodological advances have used VCs [for a review see Barisic et al. (2013)] in (1) gaze-contingent eye-tracking paradigms (Schilbach et al., 2010; Wilms et al., 2010; Pfeiffer et al., 2011; Grynszpan et al., 2012), (2) live interactions via video feeds, as in bi-directional real-time video streams (Redcay et al., 2010; Saito et al., 2010; Tanabe et al., 2012), and (3) dual eye tracking in two (real or virtual) person setups (Barisic et al., 2013). In the first approach, the gaze is used to control contingent behavior of VCs, who are agents with preprogrammed reactions contingent upon an individual's behavior, hence creating merely the illusion of an "online" real-time interaction (Barisic et al., 2013). The second approach does not make use of virtual technology; therefore, the experimenter is unable to interfere with an interaction, except for substituting or delaying the real-time video stream (Barisic et al., 2013). Consequently, only the third approach is a real interactive one, able to make full use of avatar technology. In this line, Barisic et al. (2013) present the implementation of a dual eye-tracking setup enabling true reciprocity and coordination in a social interaction of two individuals represented by avatars. In this setup, the eye gaze can be either an active part of the task or it can be a dependent measure that can be correlated with other behaviors of interest (Barisic et al., 2013). Furthermore, in line with the TSI approach, this paradigm allows both the VE and the VCs to be fully and systematically controlled in terms of their outer appearance and behavior.

A further promising approach in terms of neuroimaging possibilities, which open up another level of analysis in this line of 
paradigms, is hyperscanning. It allows the simultaneous measurement of brain activity in two interacting individuals situated in different neuroimaging environments (electroencephalography: Astolfi et al., 2010; Dumas et al., 2010; Kourtis et al., 2010; Lachat et al., 2012; near-infrared spectroscopy: Cui et al., 2012; magnetoencephalography: Baess et al., 2012; Hirata et al., 2014; fMRI: Montague et al., 2002; King-Casas et al., 2005; Saito et al., 2010; Tanabe et al., 2012). In particular, the development of fMRI hyperscanning allows the synchronization of functional image acquisition across multiple subjects and scanners, the performance of cross-brain correlation analyses and, thus, permits the measurement of inter-brain activity coherence during the act of interacting. Combined with using VCs as stimuli, hyperscanning would allow researchers to measure the reactions of multiple participants to shared social situation in a VR environment (see also "Virtual characters as real-time interaction partners" and "brain imaging setups" in Figure 1).

\section{VIRTUAL CHARACTERS AND SOCIAL PRESENCE}

The acceptance of VCs as intentional and engaging social entities has also been described as "copresence" (also referred to as "social presence") to describe a communicator's sense of awareness of the presence of an interaction partner [for a review, see Biocca et al. (2003)]. While we can conclude that numerous studies by different research groups show that people can perceive both forms of representations (agents or avatars) comparably to real human beings, it is important to note that findings are not entirely conclusive (cf. Perani et al., 2001; Mar et al., 2007; Moser et al., 2007). The emergence of copresence, which can be measured both at the behavioral and neural level, is mediated by several factors, and the "immersion" potential of the technology is only one of them. Such factors need to be taken into account when designing social interaction paradigms using VCs. In the following, these factors are described.

\section{Anthropomorphism (i.e., human form realism)}

The consensus in the literature argues that the more anthropomorphic or humanlike a character looks like, the more likely they are accepted by an observer (Garau, 2003). On a neural level, the activity of neural regions of the SNN, which are consistently associated with social-cognitive processing, is correlated with the increasing degree of realism of a character (Mar et al., 2007), or anthropomorphism of an interaction partner while performing the prisoner's dilemma game (Krach et al., 2008). In a similar vein, it has been suggested that the $\mathrm{AON}$ is tuned to realistic representations of conspecifics (Perani et al., 2001; Shimada, 2010).

Behavioral realism (i.e., humanlike movements or behavior patterns) In observational paradigms, the $\mathrm{AON}$ has been found to be preferentially activated when processing biological motion, i.e., movements with kinematics characterized by a smooth velocity profile [Dayan et al., 2007; Casile et al., 2010; but see also Cross et al. (2012) and Georgescu et al. (2014)]. In interactive paradigms, aspects of behavioral realism related to the responsiveness of or feedback from the VC are crucial for the emergence of social presence (Garau, 2003). Indeed, even subtle manipulations increasing an avatar's responsiveness (e.g., maintaining eye contact, realistic blinking rates) can influence participant's social responses to
VCs suggesting that on some levels people can respond to virtual humans as social entities even in the absence of complex interactions (Bailenson et al., 2001, 2002; Garau et al., 2005).

\section{The interaction between anthropomorphism and behavioral realism and the "uncanny valley" effect}

Generally, it has been suggested that the sensitivity to biological motion is independent of how detailed the character's body is (Chaminade et al., 2007; McDonnell et al., 2008). However, according to the "uncanny valley" theory, the more a VC looks like a real human, the more likely subtle imperfections are perceived as awkward and therefore allocate attention to other processes than the targeted social-cognitive processes (Mori, 1970; Garau, 2003). Hence, even subtle flaws in rendering or expression may cause irritations when extremely detailed anthropomorphic, fully rendered $3 \mathrm{D}$ characters are used. In this regard, VCs that are highly realistic might set up high expectations also with respect to behavior realism. Hence, a mismatch between form and behavioral realism can lead to a perception of inconsistency (Garau, 2003; Nowak and Biocca, 2003; Saygin et al., 2011). Indeed, even the most advanced motion capture technologies may find it impossible to match the level of accuracy in terms of degrees of freedom of natural human movement.

\section{Agency (the belief or knowledge about the nature of a VC)}

A top-down influence of belief about the nature of the VC (agent or avatar) may also modulate its perception [Stanley et al., 2007, 2010; Liepelt and Brass, 2010; Klapper et al., 2014; but see Press et al. (2006) and von der Pütten et al. (2010b)]. A direct comparison between the influence of belief about agency and behavioral realism on social presence revealed that believing to interact with an avatar or with an agent barely influenced the evaluation of the VC or his behavioral reactions, whereas variations in behavioral realism affected both [von der Pütten et al., 2010b; see also Nass and Moon (2000)].

\section{Observer characteristics}

It is important to note that, while VCs can elicit social presence, they tend to do so to varying degrees in different observers. Certain characteristics of the observers such as age and sex, their perceptual, cognitive and motor abilities, or prior experience with mediated environment can influence the amount of experienced social presence. For instance, participants' subjective feeling after an interaction with an embodied conversational agent, as well as their evaluation of the VC and their actual behavior was dependent upon their personality traits (von der Pütten et al., 2010a). Furthermore, an important factor to control for is the computer proficiency of the observers and their exposure to VCs. Some people have a higher affinity to computers and games that use avatars and may thus have different expectations concerning both form and behavioral realism. There is evidence that proficiency in using VEs, facilitates immersion and/or copresence, and training with artificial human stimuli can increase their credibility (Garau et al., 2005; Press et al., 2007). Similarly, Dyck et al. (2008) found that emotion recognition rates decreased for virtual but not for real faces only in participants over the age of 40 , indicating that media exposure may indeed have an influence on the recognition of non-verbal signals displayed by VCs. 


\section{VIRTUAL CHARACTERS IN NON-VERBAL BEHAVIOR RESEARCH IN HFA \\ VIRTUAL CHARACTERS AS STIMULI IN NEUROIMAGING STUDIES}

A critical prerequisite for a reasonable use of VCs in research investigating non-verbal behavior processing in HFA is that autistic individuals are engaged by VCs to the same extent as they would be by real human beings and that they do not show any differential positive or negative psychological responses to the former. Hernandez et al. (2009) performed an eye-tracking study to quantify gaze behavior in both adults with ASD and typically developing individuals while exploring static real and virtual faces with direct gaze. In concordance with the literature, participants with HFA spent less time on the eye region compared to typically developing individuals (e.g., Pelphrey et al., 2002; Rutherford and Towns, 2008; Riby and Doherty, 2009; Nakano et al., 2010; Falkmer et al., 2011). Critically, no differences were identified with regard to the exploration of the faces depending on whether they were real or virtual. With respect to the experience in IVEs, Wallace et al. (2010) have for instance shown in a usability study on HFA and typically developing children that experience of IVEs was similar across groups, and no negative sensory experiences were reported in children with HFA. We can conclude that VCs and IVEs are experienced in a similar manner by individuals with HFA and typically developing individuals, and that they can reliably be used to simulate authentic social situations in experimental settings. To our knowledge only five neuroimaging studies on non-verbal cue processing have been performed on individuals with HFA. In the following, we will review this literature (see also Table 1 for an overview and details of the paradigms).

Neuroimaging research investigating non-verbal behavior in HFA using VCs has focused mainly on face processing and more specifically on the processing of emotional expressions and eye gaze. Schulte-Rüther et al. (2011) asked participants to empathize with static virtual emotional faces and either judge the emotional state of the face ("other" condition) or report the emotions elicited in themselves by the emotional face ("self" condition). With respect to the behavioral performance, the authors found no significant differences in reaction times between HFA participants and control participants for any of the two experimental conditions. In addition, neural results showed that key areas of the SNN were activated in both controls and HFA participants. However, the authors found evidence for a functional segregation in the medial prefrontal cortex, a region which has previously been associated with mentalizing (Amodio and Frith, 2006). Direct comparisons showed that the self- and other-referential tasks, relative to the control task, engaged the dorsal medial prefrontal cortex for individuals with HFA and the ventral portion of the same region for control participants. According to the established functional characterizations of these neural regions, empathizing with other persons is likely to be triggered by emotional self-referential cognition in controls, as affective "theory of mind" components are known to recruit ventral areas of the medial prefrontal cortex region (Amodio and Frith, 2006). Conversely, HFA participants seem to engage cognitive components of "theory of mind," which are associated with the dorsal portion of the medial prefrontal cortex (Amodio and Frith, 2006).

Given that eye gaze provides a foundation for communication and social interaction (Senju and Johnson, 2009), one area of research that has particularly benefited from the use of VR techniques has been concerned with investigating the neural correlates of social gaze processing in HFA. One of the first neuroimaging studies on this subject used fMRI to show that, in HFA, brain regions involved in gaze processing are not sensitive to intentions conveyed by observed gaze shifts (Pelphrey et al., 2005). The paradigm was based on short videos of a VC shifting their gaze either "congruently" at a checkerboard that appeared in their visual field, or "incongruently" away from the checkerboard. Autistic participants engaged the same temporo-parietal network as controls to process this task, which was centered around the superior temporal sulcus. However, in contrast to the control group, their activation was not modulated by congruency. The authors suggest that an absence of contextual influence on the superior temporal sulcus region indicates a reduced understanding of different intentions of others' gaze behavior and may represent a possible mechanism underlying gaze-processing deficits reported in ASD. More recently, Pitskel et al. (2011) addressed the differential neural processing of direct and averted gaze. Participants viewed videos depicting an approaching male VC either maintaining direct gaze with the observer or averting their eyes from them. The SNN, which was more responsive to the direct relative to averted gaze in typically developing participants, was not preferentially active to direct gaze in HFA participants, indicating again a reduced understanding of different meanings of non-verbal social cues. Similarly, von dem Hagen et al. (2013) showed participants dynamic virtual faces with neutral expressions displaying either averted or direct gaze events. Their results showed that regions of the SNN were more involved in processing direct compared to averted gaze in control participants but in the opposite contrast for HFA participants, potentially indicating an increased salience of averted but not direct gaze in HFA. Finally, a study from our own research group (Georgescu et al., 2013) employed a parametric design in order to investigate the neural correlates of the influence of gaze direction and duration on person perception. We used dynamically animated faces of VCs, displaying averted gaze or direct gaze of varying durations $(1,2.5$, or $4 \mathrm{~s})$. Results showed that direct gaze as such and increasing direct gaze duration modulated the engagement of the SNN in control participants, indicating the processing of social salience and a perceived communicative intent. In HFA participants, however, regions of the SNN were more engaged by averted and decreasing amounts of gaze, while the neural response for processing increasing direct gaze in HFA was not suggestive of any social information processing.

To conclude, research using VCs as stimuli attests that they are a useful tool for the investigation of non-verbal behavior processing in HFA. In particular, the inclusion and manipulation of dynamic aspects of movement is facilitated by using VCs and is therefore able to offer unique insight into non-verbal behavior processing in HFA. As a general result, these research findings show atypical social-cognitive processing in HFA both on the behavioral and neural level, highlighting the fact that non-verbal information is less salient to individuals with HFA compared to typically developed individuals. But while the mere perception of non-verbal cues may, under certain circumstances, be comparable to that of typically developed individuals, it seems that in individuals with HFA the evaluation of such cues may rely on different cognitive strategies. 
Table 1 | Overview of neuroimaging studies using virtual characters to study non-verbal behavior processing in HFA.

\begin{tabular}{lll}
\hline Study & Participant characteristics & Experimental design and stimuli \\
\hline Pelphrey et al. (2005) & $\begin{array}{l}\text { N=10 ASD (mean age: } \\
\text { 23.2), right-handed; } \\
\text { compared to other studies }\end{array}$ & $\begin{array}{l}\text { Stimuli: short videos of a VC shifting their } \\
\text { gaze either congruently or incongruently } \\
\text { conducted in his laboratory }\end{array}$ \\
& $\begin{array}{l}\text { checkerboard } \\
\text { Eye gaze direction } \\
\text { (congruency) }\end{array}$ & $\begin{array}{l}\text { Design: } 10 \text { runs (70 trials of each } \\
\text { condition); eye tracking }\end{array}$ \\
& $\begin{array}{l}\text { Task: attend to the screen at all times, but } \\
\text { allowed to look at presented stimulus in } \\
\text { any way the wish; press a button with } \\
\end{array}$ \\
& $\begin{array}{l}\text { right or left thumb when eye movement is } \\
\text { seen, no matter whether the eyes acquire } \\
\text { the target }\end{array}$
\end{tabular}

\section{Pitskel et al. (2011) $\quad N=15$ male HFA (mean age: 23.4$)$ and 14 matched \\ fMRI}

Eye gaze direction (direct vs. averted)
$N=18$ male ASD (mean age: 27.40 ) and 18 matched controls; only 14 of each group included in final $\mathrm{AMRI}$ (ASD group: 7 AS, 7 HFA)
Stimuli: an approaching male VC maintained either direct or averted gaze with the observer

Design: one run (422s), 10 trials ( $6 \mathrm{~s}$ per trial) intertrial intervals of 12,14 , or $16 \mathrm{~s}$

Task: attend to the displays and remain alert and awake

Stimuli: three dimensional representations made of male faces, morphed to happy or sad expression (each with how or low intensity) or neutral expression $(2 \times 2 \times 2$ and $3 \times 2)$; static

Design: block design; 12 blocks with three experimental tasks, each block consisting of 6 trials (total of 192 trials)

Task: identify emotional expression of face (other) or emotion elicited in themselves by the face (self)

\section{Description of results}

Behavioral:

1. Eye tracking showed no differences between subjects with and without ASD Neural:

1. Subjects in autism do not show differences in activity of the STS and other brain regions linked to social cognitions

2. Activity in these regions was not modulated by the context of the perceived gaze shift

Behavioral:

1. Both participant groups were sensitive to the experimental manipulation, yet the gaze condition that elicits preferential neural activation differs as a function of group status Neural:

1. TD: greater activation to direct gaze in the right anterior insula (AI), bilateral caudate, left thalamus, left cerebellum, and left inferior frontal gyrus

2. HFA: greater activation to direct gaze in left cuneus, and greater activation to averted gaze in bilateral cerebellum and left inferior occipital gyrus. No correlations between activation in regions modulated by gaze condition correlated significantly with age or Full Scale 10

Right Al only showed significant differences between gaze in the typically developing group, while left LOC was only significantly modulated by gaze in the autism group

Behavioral:

1. Reaction times were faster for the other- than for the self-task and faster for the high than the low emotion intensity stimuli

2. Number of correct responses for the other-task was higher than the number of congruent responses for the self-task and higher for the high emotional intensity than the low emotional intensity stimuli

Neural:

1. Other-task vs. control task: control subjects showed differential activation in the VMPFC and precuneus/PCC, subjects with autism showed differential activation in the dMPFC 
Table 1 | Continued

Study Participant characteristics Experimental design and stimuli Description of results

\begin{tabular}{|c|c|c|c|}
\hline & & & $\begin{array}{l}\text { 2. Self-task vs. control task: control subjects } \\
\text { showed additional activations in the dMPFC, } \\
\text { left IFC, left TPJ, and right } \\
\text { 3. Cerebellum, subjects with ASD showed } \\
\text { increases in activity of left superior frontal } \\
\text { gyrus, bilateral middle frontal gyrus, bilateral } \\
\text { IFC, bilateral TPJ, ITG and temporal pole } \\
\text { 4. Conjunction of other task vs. control task and } \\
\text { self-task vs. control task: in ASD subjects, } \\
\text { conjoint activation could be observed in } \\
\text { bilateral precuneus/PCC and left dMPFC }\end{array}$ \\
\hline $\begin{array}{l}\text { Georgescu et al. (2013) } \\
\text { fMRI, eye tracking }\end{array}$ & $\begin{array}{l}N=13 \text { HFA ( } 9 \text { male, mean } \\
\text { age:31.23) and } 13 \text { matched } \\
\text { controls ( } 9 \text { male, mean age: } \\
\text { 30.23) }\end{array}$ & $\begin{array}{l}\text { Stimuli: ca. } 5 \text { s animations of } 10 \text { male and } \\
10 \text { female VC neutral faces, displaying } \\
\text { either averted or direct gaze of varying } \\
\text { duration }(1,2.5,4 \mathrm{~s})\end{array}$ & $\begin{array}{l}\text { Behavioral: } \\
\text { 1. HFA participants showed no significant } \\
\text { difference in likeability ratings depending on } \\
\text { gaze duration }\end{array}$ \\
\hline $\begin{array}{l}\text { Eye gaze direction } \\
\text { (direct vs. averted) and } \\
\text { duration }\end{array}$ & & $\begin{array}{l}\text { Design: } 2 \times 3 \text {, parametric; event-related; } \\
\text { factor ( } 1 \text { ) gaze direction (direct and } \\
\text { averted) and factor (2) gaze duration ( } 1 \text {, } \\
2.5,4 \text { s) } \\
\text { Task: judging likeability of each VC on a } \\
\text { 4-point scale }\end{array}$ & $\begin{array}{l}\text { 2. Control group rated the virtual characters as } \\
\text { increasingly likeable with increasing gaze } \\
\text { duration } \\
\text { 3. No significant group difference } \\
\text { Eye tracking: no difference in fixation on any } \\
\text { face ROI across conditions and across groups } \\
\text { Neural: } \\
\text { 1. In controls: Regions of the SNN are activated } \\
\text { by direct vs. averted gaze and by increasing } \\
\text { gaze duration perception } \\
\text { 2. In HFA: the pSTS is activated by direct } \\
\text { compared to averted gaze; no differential } \\
\text { activation for processing increasing gaze } \\
\text { duration: regions of the SNN are engaged by } \\
\text { averted compared to direct gaze and by } \\
\text { decreasing gaze duration }\end{array}$ \\
\hline $\begin{array}{l}\text { von dem Hagen et al. } \\
\text { (2013) } \\
\text { fMRI, eye tracking } \\
\text { Eye gaze direction } \\
\text { (direct vs. averted) }\end{array}$ & $\begin{array}{l}N=21 \text { male HFA and AS } \\
\text { (mean age: } 29 \text { ) and } 25 \\
\text { matched controls (mean } \\
\text { age: } 26 \text { ) }\end{array}$ & $\begin{array}{l}\text { Stimuli: animations of } 5 \text { male and } 5 \\
\text { female VC neutral faces, displaying either } \\
\text { averted or direct gaze } \\
\text { Design: block design } 21-\text { long epochs } \\
\text { Task: gender judgments }\end{array}$ & $\begin{array}{l}\text { Neural: } \\
\text { 1. No group differences in DMNb, DMNc, } \\
\text { salience, and MTL networks within or without } \\
\text { ROls } \\
\text { 2. Significantly reduced functional connectivity } \\
\text { between and within resting state networks }\end{array}$ \\
\hline
\end{tabular}

\section{VIRTUAL CHARACTERS AS REAL-TIME INTERACTION PARTNERS}

Despite the strong evidence for social processing deficits in HFA individuals, it has been documented that persons with HFA may learn to compensate their performance during social situations in structured experimental settings (Kylliäinen and Hietanen, 2004; Congiu et al., 2010). Such explicit instructions to focus on specific social contents of stimuli may cancel out the atypical performance effects and even diminish the typical hypoactivation of SNN areas (Wang et al., 2007; Schulte-Rüther et al., 2011). In a similar vein, anecdotal reports inform us that individuals with autism have particular problems during "online," real-time interactions, which require the integration of signals from a variety of channels, while the complex and unpredictable input is rapidly changing (Redcay et al., 2012; Wang and Hamilton, 2012). This is in line with the idea that ASD is a disorder of complex information processing (Minshew and Goldstein, 1998). Dynamic interactions critically impede the application of rule-based strategies to compensate for HFA-characteristic deficits in intuitive communication (Klin et al., 2003; Redcay et al., 2010). This points to the fact that "offline" social cognition paradigms as the ones described above (in "Virtual characters as stimuli in neuroimaging studies"), may fail to capture important aspects of social processing deficits in HFA, and that "online" paradigms might be more appropriate for this purpose. Thus, neuroimaging paradigms using VEs and VCs that include the complexity of dynamic social interactions, may provide a more sensitive measure of the neural basis of social and communicative 
impairments in HFA. Consequently, the combined use of VR and neuroimaging techniques offers great potential to investigate nonverbal communication in social interactions as well. Therefore, the possibility of engaging HFA in interactions in the scanner may be useful in understanding social cognition in ASD (Redcay et al., 2010).

Social interactions are characterized by a high degree of automatic interpersonal coordination (Cappella, 1981, 1996; Burgoon et al., 1993) or an above-chance probabilistic relationship between the actions of two interactants (Moran et al., 1992). A number of studies have performed kinematic analyses to investigate motor patterns expressed in social interactions and were able to show that the kinematics of an action performed by an agent acting in isolation are different from those of the very same action performed within a social communicative context and that kinematics not only carry information as to whether a social communicative action is performed in a cooperative or competitive context, but also that they cause flexible online adjustments to take place in response to a partner's actions [Georgiou et al., 2007; Becchio et al., 2008a,b; Sartori et al., 2009; for a review, see Becchio et al. (2010)]. The ability to detect an interaction partner's responses as being related to one's own is termed social contingency sensitivity (Bigelow and Rochat, 2006). Several studies using observational paradigms have already attested that individuals with ASD perceive contingency in dyadic interactions abnormally in terms of animacy perception and mental state attribution [Abell et al., 2000; Klin, 2000; Castelli et al., 2002; Klin and Jones, 2006; see also Centelles et al. (2013)]. Therefore, it has been hypothesized that this inability to detect contingency in social interactions (as either observers or participants), may be a core impairment in autism (Gergely, 2001). The inefficient contingency processing could be related to one particular non-diagnostic secondary symptom of HFA, namely atypical temporal processing. For instance, interval timing [i.e., processing of stimulus duration; for a review, see Falter and Noreika (2011); see also Georgescu et al. (2013) for duration processing for social cognition] and temporal event structure coding (Falter et al., 2012, 2013) have been found to be atypical in HFA. There is evidence for the association between temporal processing and social cognition (e.g., Moran et al., 1992; Trevarthen and Daniel, 2005; Bigelow and Rochat, 2006), Thus, atypical temporal processing might play an important yet under-investigated role in ASD by interacting with and modulating primary symptoms, like deficits in non-verbal communication and social coordination and interaction (Falter and Noreika, 2011).

One such aspect that depends on temporal processing in the social domain is motor mimicry. Elementary motor mimicry (i.e., when an observer's overt motor response is appropriated to the situation of the observed other) has been understood as a communicative act (Bavelas et al., 1986). Bailenson and Yee (2005) performed the first study to show social influence effects with a non-human, non-verbal mimicker (i.e., an imitator of the behavior of another; Chartrand and Bargh, 1999). The authors found that when an embodied virtual agent mimicked participants' head movements $4 \mathrm{~s}$ after they occurred during a social interaction, the mimicking agent was more persuasive and was rated more positively with respect to certain traits compared to non-mimickers.
The STORM (i.e., “social top-down response modulation”) model of mimicry claims that mimicry is socially top-down modulated and subtly controlled by social goals (Wang and Hamilton, 2012). For example, in typically developed individuals, social context as communicated through eye contact has been found to control mimicry by modulating the connection strength from the medial prefrontal cortex, a key region of the SNN, to regions of the AON (Wang et al., 2011). Future studies are currently being planned that will examine how different types of social information and social goals are used in the control of mimicry and whether the mimicry production and processing is abnormal in HFA (Wang and Hamilton, 2012). One particularly promising approach in this respect would be the TSI approach, similar to the one used by Bailenson and Yee (2005). This could involve creating VCs that can copy a participant by using an automatic mimicking (i.e., a computer algorithm applied to all movements), to test how people with HFA respond to and detect different social cues from the VC.

Hyperscanning (described in "Virtual characters and social presence") may be combined with experimental paradigms to characterize the neural dynamics contributing to atypical social processing in HFA (see Figure $\mathbf{1}$ for a possible setup involving eye tracking and manual response options). For instance, a recent fMRI hyperscanning study in which dyads either comprising a participant with ASD and a control participant or two control participants engaged in a gaze- vs. target cued joint attention task (Tanabe et al., 2012). Among other findings, the authors report a reduction of inter-individual coherence of intrinsic activity fluctuations in ASD-control as compared to control-control pairs in the right inferior frontal gyrus. The authors speculate that this finding might be related to decreased motor resonance for gaze behavior in these dyads.

\section{VIRTUAL CHARACTERS AS A SUPPORTIVE, EDUCATIONAL, AND THERAPEUTIC TOOL FOR HFA}

While the majority of adults with HFA consider the access to assistive therapy options as an important issue (Gawronski et al., 2011), many individuals have great difficulty finding traditional trainings and intervention approaches due to intervention costs and a lack of available specialized therapists (Bekele et al., 2013). In this line, the use of VEs and VCs offers an alternative, which could increase intervention accessibility and reduce the cost of treatment (Goodwin and Goodwin, 2008).

By enabling the simulation of a social environment, VR provides opportunities to practice dynamic and real-life social interactions in a safe environment (Krämer, 2008). Furthermore, VR possesses several advantages in terms of potential application for individuals with HFA. These are listed in the following, and while they represent independent features of VR technology, it is their combined value that offers unique potential for individuals with HFA (Parsons and Cobb, 2011).

\section{CONTROL}

The level and number of various features of the environment can be directly controlled and manipulated. This enables frequent practice and/or exposure in a variety of repeatable and adjustable situations that mimic the real world (Krämer, 2008). 


\section{FLEXIBILITY}

Increased control over the scenarios and environments allows for interfaces to be modified for individual user needs, for intervention approaches and reinforcement strategies, as well as scenarios to be customized (Strickland, 1997; Rizzo and Kim, 2005; Krämer, 2008):

\section{ERROR-FREE LEARNING}

Increased control also allows for competing or distracting stimuli to be removed from the training setting and the level of exposure to be carefully controlled (Strickland, 1997; Parsons and Mitchell, 2002; Rizzo and Kim, 2005; Krämer, 2008). Users' performance can be recorded and used for subsequent discussion. Thus, users can practice without fear of mistakes or rejection (Rizzo and Kim, 2005; Krämer, 2008).

\section{INDEPENDENT PRACTICE}

Self-guided exploration and independent practice in a safe test/training environment are enabled (Rizzo and Kim, 2005), where the user has active control over their participation (Parsons and Mitchell, 2002).

\section{ECOLOGICAL VALIDITY}

This offers greater potential for naturalistic performance measures with real-time performance feedback, hence increasing the potential for generalization (Parsons and Mitchell, 2002; Rizzo and Kim, 2005; Bellani et al., 2011; Wang and Reid, 2011).

\section{AFFINITY WITH COMPUTERS}

Finally, this approach can be particularly useful for persons with ASD, as they have been found to have a natural interest in and affinity with computers due to the predictable, consistent, and repeatable nature of technology (Parsons and Mitchell, 2002; Parsons et al., 2006; Putnam and Chong, 2008). This, in turn, could heighten their compliance and investment in the treatment (Krämer, 2008) and may be even made use of, for example, by including gaming factors to enhance user motivation to complete tasks (Rizzo and Kim, 2005).

Indeed, usability research has attested participants' explicit acknowledgment of the value of the virtual training for them (e.g., Parsons and Mitchell, 2002; Parsons et al., 2006). Research has also shown that individuals with ASD successfully acquire new information from VEs. In particular, they learn how to use the equipment quickly and show significant improvements in performance after training [for reviews, see Strickland (1997), Bellani et al. (2011), Parsons and Cobb (2011, 2013), and Wang and Reid (2011)]. Some authors have investigated the usefulness of VEs for training behaviors such as crossing the road (Josman et al., 2008) or reacting to a tornado warning (Self et al., 2007) and to aid learning of pretend play (Herrera et al., 2008). However, we will focus the following considerations on virtual training and assistive therapies on the advantage of VEs for training social and non-verbal skills.

Virtual characters have been used for individuals with HFA to provide training to teach social conventions, facilitate acquisition and exploration of social skills, and reduce stress in social situations. For instance, some social skill training scenarios involve finding a place to sit in a crowded canteen, cafe or bus, a job interview or shopping situation (Rutten et al., 2003; Parsons et al., 2006; Mitchell et al., 2007), or training collaboration skills in the context of the production of a joint narrative (Gal et al., 2009). Jarrold et al. (2013) have developed a public speaking task using IVE technology to study social attention in HFA. They used a HMD to display a virtual classroom and assess the ability of children with HFA to answer questions and simultaneously attend to nine avatar peers seated at a table. They have found that HFA, compared to controls, looked less frequently to avatar peers in the classroom while talking. Consequently, in order to train social attention, virtual training programs have been developed (Grynszpan et al., 2009; Lahiri et al., 2011a,b). For example, Lahiri et al. (2011a,b) developed a novel paradigm, able to automatically structure and adapt interactions in real-time. The platform is called the "Virtual Interactive system with Gaze-sensitive Adaptive Response Technology" (VIGART) and is capable of monitoring a user's gaze in real-time and delivering individualized feedback based on the user's dynamic gaze patterns during their interaction with a virtual other. The experimental setup involved a DVE that presented participants with social communication tasks. While the participant viewed the avatar narrating a personal story, the participant's viewing patterns were measured in real-time by acquiring gaze data and subsequently some behavioral viewing indices were computed. These episodes were followed by a short quiz on the content of the virtual other's personal story. After the participant's reply, an audio-visual feedback, which was computed based on the real-time gaze data to determine the actual time the participant spent looking at the face of the avatar during the presentation, was provided to the participant. The idea was to give indirect feedback to the participants about their viewing patterns and thereby study how that would affect the participants as the task proceeded. Preliminary data for six adolescents with ASD indicate improvement in behavioral viewing and changes in relevant eye physiological indexes of participants. Another approach was introduced by Porayska-Pomsta et al. (2012) who developed the ECHOES project. It aims to allow children with social difficulties to understand and explore social communication and interaction skills. In this learning platform, children interact with embodied virtual agents in socially realistic situations. The interaction between the child and the agents is facilitated by a combination of learning activities, designed around specific learning goals that relate to different forms of joint attention and turn-taking as well as free exploration of the environment.

The environments used in such approaches have been either single-user virtual environments (SVEs) or collaborative virtual environments (CVEs). In an SVE, a single user explores the VE and responses from the environment or a virtual agent must be preprogrammed. In a CVE, more than one user may inhabit the $\mathrm{VE}$ at the same time (for example the patient and the therapist or trainer) and can interact with each other in real-time via avatars. Users control their avatars independently and can communicate directly with each other, even when physically located in different places, through speech, movement, and gesture in the virtual space (Schroeder, 2002; Rutten et al., 2003; Moore et al., 2005; Bellani et al., 2011; Millen et al., 2011; Parsons and Cobb, 2013). For example, the COSPATIAL project developed and evaluated collaborative technologies for engaging children with autism in social 
communication, involving perspective-taking, conversation, and collaboration games (Millen et al., 2011). Rutten et al. (2003) performed a usability study to investigate the potential of CVEs for individuals with ASD. They used role-play situations in either a meeting room or a social cafe. Although the emphasis lied on verbal communication between avatars, users were able to activate some basic non-verbal signals like a handshake and a smiling, neutral or frowning facial expression. The authors conclude that CVEs provide less inherent structure than SVEs and more scaffolding of learning is usually required to keep interactions flowing. Nevertheless, they offer increased flexibility for training in social skills, which do not rely on a fixed protocol hence providing opportunities for social skill practice in a less structured, yet more naturalistic and ecologically valid manner (Rutten et al., 2003). The authors suggest that the most productive setup in communication outcome for a CVE would be when a teacher or trainer supports the users, and a confederate plays the role of another avatar. In a similar line, Parsons et al. (2006) argue that the so-called "facilitators" in a training or intervention are an essential part of the learning process, helping the user interpret what is happening in the scene, take another's perspective and make appropriate responses accordingly. The role of the facilitator should always be adequately planned and provided for as an integral design feature of VEs for teaching of social skills (Parsons et al., 2006). Given that ASD have been associated with executive dysfunction (Hill, 2004) and that complexity in terms of task demands and sensory input information may be challenging for autistic individuals (Minshew and Goldstein, 1998; Redcay et al., 2012), it is essential to invest into optimal design research for platforms and software targeted at HFA individuals (Grynszpan et al., 2005, 2008; Wallace et al., 2010; Menzies, 2011). In this line, transformed virtual interactions might be a promising approach (Bailenson et al., 2004). Tracking non-verbal signals and rendering them via avatars allows for a strategic decoupling of communication (Bailenson et al., 2004), which would allow to alter the exchanged information between sender and receiver and increase or decrease gradually the level of complexity of the social situation, while still facilitating error-free learning.

Collaborative virtual environments also bear advantages in terms of non-verbal decoding and encoding skills. In the nonverbal domain, CVEs have been used to examine and investigate the ability to recognize emotions (Moore et al., 2005; Fabri et al., 2007) and also teaching students how to manifest their emotions and understand those of other people (Cheng and Ye, 2010). These studies found a good performance in identifying emotions and an improvement in social performance after the intervention. Krämer (2008) suggests three important requirements for a non-verbal skills training: (1) realistic setting that requires both decoding and encoding of non-verbal cues; (2) immediate non-verbal feedback from the interaction partner; and (3) feedback that is given not only with regard to demonstrative cues of the user, but also with regard to subtle aspects of their behavior, like the movement speed or quality. Indeed, VEs and virtual training partners seem to allow the development of training paradigms that fulfill these criteria.

While most training approaches using VCs and VEs have been developed for children and adolescents, Kandalaft et al. (2013) have developed the first Virtual Reality Social Cognition Training
(VR-SCT), targeted at the adult HFA population. The intervention is using a CVE paradigm and a DVE setup and focuses on enhancing social skills, social cognition and social functioning. Its feasibility was tested on a group of eight HFA adults, who completed a total of 10 sessions across 5 weeks. Results showed significant increases on social-cognitive measures of theory of mind and emotion recognition, as well as in real-life social and occupational functioning.

Indeed, the literature is increasingly recognizing the potential benefits of VR in supporting the learning process, particularly related to social situations, mostly in children and adolescents with autism [for reviews, see Strickland (1997), Bellani et al. (2011), and Parsons and Cobb (2011)] and also in adults (Kandalaft et al., 2013). Nevertheless, some challenges need to be mentioned as well. Current approaches only involve small samples and more randomized controlled trials with treatment manipulations and matched control groups need to be performed in order to show the effectiveness of a certain training and whether the improvements can transfer to real-life situations. Moreover, while virtual technologies are rapidly advancing, developing training or therapeutic tools using VCs and VEs involve a great amount of time, effort, and resources, as well as a multidisciplinary dialog.

\section{CONCLUSION}

In conclusion, we have argued that the use of VCs can be of great value for experimental paradigms of social cognition, in particular for such paradigms concerned with non-verbal behavior production and perception. There are several points to note with respect to challenges inherent in the use of VCs and VEs. First, the compromise or tradeoff between ecological validity and experimental control constitutes both an advantage and a limitation of the approach. Second, individuals may have varying degrees of exposure to or experience with VCs, which may influence their expectations during observation of or interaction with them. Third, different age groups may also react differently to the stimuli and settings and may require different tasks and social situations to be implemented. Furthermore, limitations may also arise from the time and effort that needs to be invested in developing virtual and neuroimaging technologies. In a similar line, these developments need to take place in the context of multidisciplinary research endeavors, which brings an interesting set of challenges on its own (i.e., fruitful collaboration and communication of experts across disciplines). On a positive note, De Gelder and Hortensius (2014) summarize that the use of VR will give the field of affective and social neuroscience valuable and important tools to grasp the full extent of the social world in a well-controlled manner. We have argued that artificial humans are a useful and valid tool to overcome common methodological problems in nonverbal behavior research and may offer an efficient solution for the development of real-time "online" social interaction studies using the TSI approach. This would potentially allow to "reverse engineer" social cognition (Blascovich et al., 2002), by enabling a detailed and systematic examination of the contribution of various real-time factors in human social interaction. Moreover, not only can VCs inform us about human social cognition, both typical and atypical, but they can also contribute to the development of design and methodology for creating interactive agents (Vogeley 
and Bente, 2010). We have also argued that VCs and environments are a valuable tool for the supportive therapies and the training of social skills and non-verbal decoding in HFA, as they provide a safe, repeatable and diversifiable learning environment. In addition, the growing trend toward CVE setups becomes evident for therapeutic technologies as well. The methodology for designing interactive multimodal technology for autistic persons requires extensive research and multidisciplinary expertise including developmental psychology, visual arts, human-computer interaction, artificial intelligence, education (Porayska-Pomsta et al., 2012). Future research can additionally investigate how newly acquired skills trough such training programs are transferred to the real world and describe their impact on a neural level (Bellani et al., 2011).

\section{ACKNOWLEDGMENTS}

We would like to thank Ralf Tepest for his helpful feedback with an earlier version of this manuscript and Marius Jonas and Susanne Holocher for help with the literature search.

\section{REFERENCES}

Abell, F., Happé, F., and Frith, U. (2000). Do triangles play tricks? Attribution of mental states to animated shapes in normal and abnormal development. Cogn. Dev. 15, 1-16. doi:10.1016/S0885-2014(00)00014-9

Adolphs, R., Tranel, D., and Damasio, A. R. (1998). The human amygdala in social judgment. Nature 393, 470-474. doi:10.1038/30982

Ambady, N., and Rosenthal, R. (1992). Thin slices of expressive behavior as predictors of interpersonal consequences: a meta-analysis. Psychol. Bull. 111, 256-274. doi:10.1037/0033-2909.111.2.256

Amodio, D. M., and Frith, C. D. (2006). Meeting of minds: the medial frontal cortex and social cognition. Nat. Rev. Neurosci. 7, 268-277. doi:10.1038/nrn1884

Argyle, M. (1988). Bodily Communication. London: Methuen.

Ashwin, C., Baron-Cohen, S., Wheelwright, S., O’Riordan, M., and Bullmore, E. T. (2007). Differential activation of the amygdala and the "social brain" during fearful face-processing in Asperger syndrome. Neuropsychologia 45, 2-14. doi:10.1016/j.neuropsychologia.2006.04.014

Astolfi, L., Toppi, J., De Vico Fallani, F., Vecchiato, G., Salinari, S., Mattia, D., et al. (2010). Neuroelectrical hyperscanning measures simultaneous brain activity in humans. Brain Topogr. 23, 243-256. doi:10.1007/s10548-010-0147-9

Baess, P., Zhdanov, A., Mandel, A., Parkkonen, L., Hirvenkari, L., Makela, J. P., et al. (2012). MEG dual scanning: a procedure to study real-time auditory interaction between two persons. Front. Hum. Neurosci. 6:83. doi:10.3389/fnhum.2012. 00083

Bailenson, J. N., Beall, A. C., Loomis, J., Blascovich, J., and Turk, M. (2004). Transformed social interaction: decoupling representation from behavior and form in collaborative virtual environments. Presence (Camb.) 13, 428-441. doi:10.1162/1054746041944803

Bailenson, J. N., and Blascovich, J. (2004). “Avatars," in Encyclopedia of HumanComputer Interaction, ed. W. S. Bainbridge (Great Barrington, MA: Berkshire Publishing Group), 64-68.

Bailenson, J. N., Blascovich, J., Beall, A. C., and Loomis, J. M. (2001). Equilibrium theory revisited: mutual gaze and personal space in virtual environments. Presence (Camb.) 10, 583-598. doi:10.1162/105474601753272844

Bailenson, J. N., and Yee, N. (2005). Digital chameleons: automatic assimilation of nonverbal gestures in immersive virtual environments. Psychol. Sci. 16, 814-819. doi:10.1111/j.1467-9280.2005.01619.x

Bailenson, J. N., and Yee, N. (2007). Virtual interpersonal touch and digital chameleons. J. Nonverbal Behav. 31, 225-242. doi:10.1007/s10919-007-0034-6

Bailenson, J. N., Yee, N., Merget, D., and Schroeder, R. (2006). The effect of behavioral realism and form realism of real-time avatar faces on verbal disclosure, nonverbal disclosure, emotion recognition, and copresence in dyadic interaction. Presence (Camb.) 15, 359-372. doi:10.1162/pres.15.4.359

Bailenson, N., Beall, A. C., and Blascovich, J. (2002). Mutual gaze and task performance in shared virtual environments. J. Vis. Comput. Animat. 13, 1-8. doi:10.1002/vis.297
Barisic, I., Timmermans, B., Pfeiffer, U. J., Bente, G., Vogeley, K., and Schilbach, L. (2013). "In it together: using dual eyetracking to investigate real-time social interactions," in Proceedings from SIGCHI Conference on Human Factors in Computing Systems, Paris.

Baron-Cohen, S. (1995). Mindblindness: An Essay on Autism and Theory of Mind. Cambridge: MIT Press.

Baron-Cohen, S., Ring, H. A., Wheelwright, S., Bullmore, E. T., Brammer, M. J., Simmons, A., et al. (1999). Social intelligence in the normal and autistic brain: an fMRI study. Eur. J. Neurosci. 11, 1891-1898. doi:10.1046/j.1460-9568.1999. 00621.x

Baron-Cohen, S., Wheelwright, S., and Jolliffe, T. (1997). Is there a "language of the eyes"? Evidence from normal adults, and adults with autism or Asperger syndrome. Vis. Cogn. 4, 311-331. doi:10.1080/713756761

Baumann, S., Neff, C., Fetzick, S., Stangl, G., Basler, L., Vereneck, R., et al. (2003). A virtual reality system for neurobehavioral and functional MRI studies. Cyberpsychol. Behav. 6, 259-266. doi:10.1089/109493103322011542

Bavelas, J. B., Black, A., Lemery, C. R., and Mullett, J. (1986). "I show how you feel": motor mimicry as a communicative act. J. Pers. Soc. Psychol. 50, 322-329. doi:10.1037/0022-3514.50.2.322

Becchio, C., Sartori, L., Bulgheroni, M., and Castiello, U. (2008a). Both your intention and mine are reflected in the kinematics of my reach-to-grasp movement. Cognition 106, 894-912. doi:10.1016/j.cognition.2007.05.004

Becchio, C., Sartori, L., Bulgheroni, M., and Castiello, U. (2008b). The case of Dr. Jekyll and Mr. Hyde: a kinematic study on social intention. Conscious. Cogn. 17, 557-564. doi:10.1016/j.concog.2007.03.003

Becchio, C., Sartori, L., and Castiello, U. (2010). Toward you: the social side of actions. Curr. Dir. Psychol. Sci. 19, 183-188. doi:10.1177/0963721410370131

Bekele, E., Zheng, Z., Swanson, A., Crittendon, J., Warren, Z., and Sarkar, N. (2013). Understanding how adolescents with autism respond to facial expressions in virtual reality environments. IEEE Trans. Vis. Comput. Graph 19, 711-720. doi:10.1109/TVCG.2013.42

Bellani, M., Fornasari, L., Chittaro, L., and Brambilla, P. (2011). Virtual reality in autism: state of the art. Epidemiol. Psychiatr. Sci 20, 235-238. doi:10.1017/ S2045796011000448

Bente, G., Eschenburg, F., and Aelker, L. (2007a). "Effects of simulated gaze on social presence, person perception and personality attribution in avatar-mediated communication," in Proceedings of the 10th Annual International Workshop on Presence (Barcelona), 207-214.

Bente, G., Eschenburg, F., and Krämer, N. C. (2007b). "The eyes have it. Socioemotional effects of computer-simulated gaze in avatar-based interactions," in Proceedings of the HCI Conference, Beijing.

Bente, G., and Krämer, N. C. (2011). "Virtual gestures: embodiment and nonverbal behavior in computer-mediated communication," in Face-To-Face Communication Over the Internet: Issues, Research, Challenges, eds A. Kappas and N. C. Krämer (Cambridge: Cambridge University Press), 176-209.

Bente, G., Krämer, N. C., and Eschenburg, F. (2008). "Is there anybody out there? Analyzing the effects of embodiment and nonverbal behavior in avatar-mediated communication," in Mediated Interpersonal Communication, eds E. A. Konijn, S. Utz, M. Tanis, and S. B. Barnes (New York, NY: Routledge), 131-157.

Bente, G., Petersen, A., Krämer, N. C., and De Ruiter, J. P. (2001). Transcriptbased computer animation of movement: evaluating a new tool for nonverbal behavior research. Behav. Res. Methods Instrum. Comput. 33, 303-310. doi:10.3758/BF03195383

Bigelow, A. E., and Rochat, P. (2006). Two-month-old infants' sensitivity to social contingency in mother-infant and stranger-infant interaction. Infancy 9 , 313-325. doi:10.1207/s15327078in0903_3

Biocca, F., Harms, C., and Burgoon, J. K. (2003). Toward a more robust theory and measure of social presence: review and suggested criteria. Presence (Camb.) 12, 456-480. doi:10.1162/105474603322761270

Birdwhistell, R. L. (1970). Kinesics and Context: Essays on Body Motion Communication. Philadelphia: University of Pennsylvania Press.

Blascovich, J., Loomis, J., Beall, A. C., Swinth, K. R., Hoyt, C. L., and Bailenson, J. N. (2002). Immersive virtual environment technology as a methodological tool for social psychology. Psychol. Inq. 13, 103-124. doi:10.1207/S15327965PLI1302_01

Bohil, C. J., Alicea, B., and Biocca, F. A. (2011). Virtual reality in neuroscience research and therapy. Nat. Rev. Neurosci. 12, 752-762. doi:10.1038/nrn3122

Burgoon, J. K. (1994). "Nonverbal signals," in Handbook of Interpersonal Communication, eds M. L. Knapp and G. F. Miller (Thousand Oaks, CA: Sage), 450-507. 
Burgoon, J. K., Buller, D. B., and Woodall, W. G. (1989). Nonverbal Communication: The Unspoken Dialogue. New York, NY: Harper and Row.

Burgoon, J. K., Dillman, L., and Stem, L. A. (1993). Adaptation in dyadic interaction: defining and operationalizing patterns of reciprocity and compensation. Commun. Theory 3, 295-316. doi:10.1111/j.1468-2885.1993.tb00076.x

Cappella, J. N. (1996). "Dynamic coordination of vocal and kinesic behavior in dyadic interaction: methods, problems, and interpersonal outcomes," in Dynamic Patterns in Communication Processes, eds J. Watt and C. A. Van Lear (Thousand Oaks, CA: Sage), 353-386.

Cappella, J. N. (1981). Mutual influence in expressive behavior: adult - adult and infant - adult dyadic interaction. Psychol. Bull. 89, 101-132. doi:10.1037/00332909.89.1.101

Casile, A., Dayan, E., Caggiano, V., Hendler, T., Flash, T., and Giese, M. A. (2010). Neuronal encoding of human kinematic invariants during action observation. Cereb. Cortex 20, 1647-1655. doi:10.1093/cercor/bhp229

Castelli, F., Frith, C., Happé, F., and Frith, U. (2002). Autism, Asperger syndrome and brain mechanisms for the attribution of mental states to animated shapes. Brain 125, 1839-1849. doi:10.1093/brain/awf189

Centelles, L., Assaiante, C., Etchegoyhen, K., Bouvard, M., and Schmitz, C. (2013). From action to interaction: exploring the contribution of body motion cues to social understanding in typical development and in autism spectrum disorders. J. Autism Dev. Disord. 43, 1140-1150. doi:10.1007/s10803-012-1655-0

Chaminade, T., Hodgins, J., and Kawato, M. (2007). Anthropomorphism influences perception of computer-animated characters' actions. Soc. Cogn. Affect. Neurosci. 2, 206-216. doi:10.1093/scan/nsm017

Chartrand, T. L., and Bargh, J. A. (1999). The chameleon effect: the perceptionbehavior link and social interaction. J. Pers. Soc. Psychol. 76, 893-910. doi:10. 1037/0022-3514.76.6.893

Cheng, Y., and Ye, J. (2010). Exploring the social competence of students with autism spectrum conditions in a collaborative virtual learning environment - the pilot study. Comput. Educ. 54, 1068-1077. doi:10.1016/j.compedu.2009.10.011

Choi, V. S., Gray, H. M., and Ambady, N. (2005). “The glimpsed world: unintended communication and unitended perception," in The New Unconscious, eds R. R. Hassin, J. S. Uleman, and J. A. Bargh (New York, NY: Oxford University Press), 309-333.

Chovil, N. (1991). Social determinants of facial displays. J. Nonverbal Behav. 15, 141-154. doi:10.1007/BF01672216

Congiu, S., Schlottmann, A., and Ray, E. (2010). Unimpaired perception of social and physical causality, but impaired perception of animacy in high functioning children with autism. J. Autism Dev. Disord. 40, 39-53. doi:10.1007/s10803-0090824-2

Critchley, H. D., Daly, E. M., Bullmore, E. T., Williams, S. C., Van Amelsvoort, T., Robertson, D. M., et al. (2000). The functional neuroanatomy of social behaviour: changes in cerebral blood flow when people with autistic disorder process facial expressions. Brain 123(Pt 11), 2203-2212. doi:10.1093/brain/123. 11.2203

Cross, E. S., Liepelt, R., de C. Hamilton, A. F., Parkinson, J., Ramsey, R., Stadler, W., et al. (2012). Robotic movement preferentially engages the action observation network. Hum. Brain Mapp. 33, 2238-2254. doi:10.1002/hbm.21361

Cruz-Neira, C., Sandin, D. J., and DeFanti, T. A. (1993). "Surround-screen projection-based virtual reality: the design and implementation of the CAVE," in Proceedings of the 20th Annual Conference on Computer Graphics and Interactive Techniques SIGGRAPH '93 (New York, NY: ACM Press), 135-142.

Cui, X., Bryant, D. M., and Reiss, A. L. (2012). NIRS-based hyperscanning reveals increased interpersonal coherence in superior frontal cortex during cooperation. Neuroimage 59, 2430-2437. doi:10.1016/j.neuroimage.2011.09.003

David, N. (2012). New frontiers in the neuroscience of the sense of agency. Front. Hum. Neurosci. 6:161. doi:10.3389/fnhum.2012.00161

Dayan, E., Casile, A., Levit-Binnun, N., Giese, M. A., Hendler, T., and Flash, T. (2007). Neural representations of kinematic laws of motion: evidence for action-perception coupling. Proc. Natl. Acad. Sci. U.S.A. 104, 20582-20587. doi:10.1073/pnas.0710033104

De Gelder, B., and Hortensius, R. (2014). "The many faces of the emotional body," in New Frontiers in Social Neuroscience, eds J. Decety and Y. Christen (Springer), 153-164.

Dratsch, T., Schwartz, C., Yanev, K., Schilbach, L., Vogeley, K., and Bente, G. (2013). Getting a grip on social gaze: control over others' gaze helps gaze detection in high-functioning autism. J. Autism Dev. Disord. 43, 286-300. doi:10.1007/s10803-012-1569-x
Dumas, G. (2011). Towards a two-body neuroscience. Commun. Integr. Biol. 4, 349-352. doi:10.4161/cib.4.3.15110

Dumas, G., Nadel, J., Soussignan, R., Martinerie, J., and Garnero, L. (2010). Inter-brain synchronization during social interaction. PLoS ONE 5:e12166. doi:10.1371/journal.pone.0012166

Dyck, M., Winbeck, M., Leiberg, S., Chen, Y., Gur, R. C., Gur, R. C., et al. (2008). Recognition profile of emotions in natural and virtual faces. PLoS ONE 3:e3628. doi:10.1371/journal.pone.0003628

Fabri, M., Elzouki, S. Y. A., and Moore, D. (2007). "Emotionally expressive avatars for chatting, learning and therapeutic intervention," in Human-Computer Interaction. HCI Intelligent Multimodal Interaction Environments Lecture Notes in Computer Science, ed. J. A. Jacko (Berlin: Springer), 275-285.

Falkmer, M., Bjällmark, A., Larsson, M., and Falkmer, T. (2011). Recognition of facially expressed emotions and visual search strategies in adults with Asperger syndrome. Res. Autism Spectr. Disord. 5, 210-217. doi:10.1016/j.rasd.2010.03.013

Falter, C. M., Braeutigam, S., Nathan, R., Carrington, S., and Bailey, A. J. (2013) Enhanced access to early visual processing of perceptual simultaneity in autism spectrum disorders. J. Autism Dev. Disord. 43, 1857-1866. doi:10.1007/s10803012-1735- 1

Falter, C. M., Elliott, M. A., and Bailey, A. J. (2012). Enhanced visual temporal resolution in autism spectrum disorders. PLoS ONE 7:e32774. doi:10.1371/journal. pone. 0032774

Falter, C. M., and Noreika, V. (2011). Interval timing deficits and abnormal cognitive development. Front. Integr. Neurosci. 5:26. doi:10.3389/fnint.2011.00026

Frith, C. D. (2007). The social brain? Philos. Trans. R. Soc. Lond. B Biol. Sci. 362, 671-678. doi:10.1098/rstb.2006.2003

Gal, E., Bauminger, N., Goren-Bar, D., Pianesi, F., Stock, O., Zancanaro, M., et al. (2009). Enhancing social communication of children with high-functioning autism through a co-located interface. AI Soc. 24, 75-84. doi:10.1007/s00146009-0199-0

Gallagher, H. L., and Frith, C. D. (2003). Functional imaging of "theory of mind". Trends Cogn. Sci. (Regul. Ed.) 7, 77-83. doi:10.1016/S1364-6613(02)00025-6

Gallagher, H. L., and Frith, C. D. (2004). Dissociable neural pathways for the perception and recognition of expressive and instrumental gestures. Neuropsychologia 42, 1725-1736. doi:10.1016/j.neuropsychologia.2004.05.006

Garau, M. (2003). The Impact of Avatar Fidelity on Social Interaction in Virtual Environments. Ph.D. thesis, Department of Computer Science, University College London, London.

Garau, M., Slater, M., Pertaub, D.-P., and Razzaque, S. (2005). The responses of people to virtual humans in an immersive virtual environment. Presence (Camb.) 14, 104-116. doi:10.1089/cpb.2009.0192

Gawronski, A., Kuzmanovic, B., Georgescu, A., Kockler, H., Lehnhardt, F.-G., Schilbach, L., et al. (2011). Expectations concerning psychotherapy of highfunctioning adults with autism spectrum disorders. Fortschr. Neurol. Psychiatr. 79, 647-654. doi:10.1055/s-0031-1281734

Georgescu, A. L., Kuzmanovic, B., Santos, N. S., Tepest, R., Bente, G., Tittgemeyer, M., et al. (2014). Perceiving nonverbal behavior: neural correlates of processing movement fluency and contingency in dyadic interactions. Hum. Brain Mapp. 35, 1362-1378. doi:10.1002/hbm.22259

Georgescu, A. L., Kuzmanovic, B., Schilbach, L., Tepest, R., Kulbida, R., Bente, G., et al. (2013). Neural correlates of "social gaze" processing in high-functioning autism under systematic variation of gaze duration. Neuroimage Clin. 3, 340-351. doi:10.1016/j.nicl.2013.08.014

Georgiou, I., Becchio, C., Glover, S., and Castiello, U. (2007). Different action patterns for cooperative and competitive behaviour. Cognition 102, 415-433. doi:10.1016/j.cognition.2006.01.008

Gergely, G. (2001). The obscure object of desire: "nearly, but clearly not, like me": contingency preference in normal children versus children with autism. Bull. Menninger Clin. 65, 411-426. doi:10.1521/bumc.65.3.411.19853

Goodwin, M. S., and Goodwin, M. S. (2008). Enhancing and accelerating the pace of autism research and treatment: the promise of developing innovative technology. Focus Autism Other Dev. Disabl. 23, 125-128. doi:10.1177/ 1088357608316678

Grammer, K. (1990). Strangers meet: laughter and nonverbal signs of interest in opposite-sex encounters. J. Nonverbal Behav. 14, 209-236. doi:10.1007/ BF00989317

Grammer, K., Honda, M., Juette, A., and Schmitt, A. (1999). Fuzziness of nonverbal courtship communication unblurred by motion energy detection. J. Pers. Soc. Psychol. 77, 487-508. doi:10.1037/0022-3514.77.3.487 
Grammer, K., Schiefenhövel, W., Schleidt, M., Lorenz, B., and Eibl-Eibesfeldt, I. (1988). Patterns on the face: the eyebrow flash in crosscultural comparison. Ethology 77, 279-299. doi:10.1111/j.1439-0310.1988.tb00211.x

Grèzes, J., Pichon, S., and De Gelder, B. (2007). Perceiving fear in dynamic body expressions. Neuroimage 35, 959-967. doi:10.1016/j.neuroimage.2006.11.030

Grynszpan, O., Martin, J.-C., and Nadel, J. (2005). "Human computer interfaces for autism: assessing the influence of task assignment and output modalities," in CHI '05 Extended Abstracts on Human Factors in Computing Systems CHI EA '05 (New York, NY: ACM Press), 1419-1422.

Grynszpan, O., Martin, J.-C., and Nadel, J. (2008). Multimedia interfaces for users with high functioning autism: an empirical investigation. Int. J. Hum. Comput. Stud. 66, 628-639. doi:10.1016/j.ijhcs.2008.04.001

Grynszpan, O., Nadel, J., Constant, J., Le Barillier, F., Carbonell, N., Simonin, J., et al. (2009). "A new virtual environment paradigm for high functioning autism intended to help attentional disengagement in a social context bridging the gap between relevance theory and executive dysfunction," in Virtual Rehabilitation International Conference (Haifa: IEEE), 51-58.

Grynszpan, O., Simonin, J., Martin, J.-C., and Nadel, J. (2012). Investigating social gaze as an action-perception online performance. Front. Hum. Neurosci. 6:94. doi:10.3389/fnhum.2012.00094

von dem Hagen, E. A., von dem Stoyanova, R. S., Rowe, J. B., Baron-Cohen, S., and Calder, A. J. (2013). Direct gaze elicits atypical activation of the theoryof-mind network in autism spectrum conditions. Cereb. Cortex 24, 1485-1492. doi:10.1093/cercor/bht003

Hari, R., and Kujala, M. V. (2009). Brain basis of human social interaction: from concepts to brain imaging. Physiol. Rev. 89, 453-479. doi:10.1152/physrev.00041. 2007

Hernandez, N., Metzger, A., Magné, R., Bonnet-Brilhault, F., Roux, S., Barthelemy, C., et al. (2009). Exploration of core features of a human face by healthy and autistic adults analyzed by visual scanning. Neuropsychologia 47, 1004-1012. doi:10.1016/j.neuropsychologia.2008.10.023

Herrera, G., Alcantud, F., Jordan, R., Blanquer, A., Labajo, G., and De Pablo, C. (2008). Development of symbolic play through the use of virtual reality tools in children with autistic spectrum disorders: two case studies. Autism 12, 143-157. doi: $10.1177 / 1362361307086657$

Hill, E. L. (2004). Evaluating the theory of executive dysfunction in autism. Dev. Rev. 24, 189-233. doi:10.1016/j.dr.2004.01.001

Hirata, M., Ikeda, T., Kikuchi, M., Kimura, T., Hiraishi, H., Yoshimura, Y., et al. (2014). Hyperscanning MEG for understanding mother-child cerebral interactions. Front. Hum. Neurosci. 8:118. doi:10.3389/fnhum.2014.00118

Hoyt, C. L., Blascovich, J., and Swinth, K. R. (2003). Social inhibition in immersive virtual environments. Presence (Camb.) 12, 183-195. doi:10.1162/ 105474603321640932

Jarrold, W., Mundy, P., Gwaltney, M., Bailenson, J., Hatt, N., McIntyre, N., et al. (2013). Social attention in a virtual public speaking task in higher functioning children with autism. Autism Res. 6, 393-410. doi:10.1002/aur.1302

Josman, M., Ben-Chaim, H. M., Friedrich, S., and Weiss, P. L (2008). Effectiveness of virtual reality for teaching street-crossing skills to children and adolescents with autism. Int. J. Disabil. Dev. Educ. 7, 49-56. doi:10.1515/IJDHD.2008.7.1.49

Kandalaft, M. R., Didehbani, N., Krawczyk, D. C., Allen, T. T., and Chapman, S. B. (2013). Virtual reality social cognition training for young adults with highfunctioning autism. J. Autism Dev. Disord. 43, 34-44. doi:10.1007/s10803-0121544-6

King-Casas, B., Tomlin, D., Anen, C., Camerer, C. F., Quartz, S. R., and Montague, P. R. (2005). Getting to know you: reputation and trust in a two-person economic exchange. Science 308, 78-83. doi:10.1126/science.1108062

Klapper, A., Ramsey, R., Wigboldus, D., and Cross, E. S. (2014). The control of automatic imitation based on bottom-up and top-down cues to animacy: insights from brain and behavior. J. Cogn. Neurosci. 26, 2503-2513. doi:10.1162/jocn_a_ 00651

Klin, A. (2000). Attributing social meaning to ambiguous visual stimuli in higherfunctioning autism and Asperger syndrome: the social attribution task. J. Child Psychol. Psychiatry 41, 831-846. doi:10.1111/1469-7610.00671

Klin, A., and Jones, W. (2006). Attributing social and physical meaning to ambiguous visual displays in individuals with higher-functioning autism spectrum disorders. Brain Cogn. 61, 40-53. doi:10.1016/j.bandc.2005.12.016

Klin, A., Jones, W., Schultz, R., and Volkmar, F. (2003). The enactive mind, or from actions to cognition: lessons from autism. Philos. Trans. R. Soc. Lond. B Biol. Sci. 358, 345-360. doi:10.1098/rstb.2002.1202
Konvalinka, I., and Roepstorff, A. (2012). The two-brain approach: how can mutually interacting brains teach us something about social interaction? Front. Hum. Neurosci. 6:215. doi:10.3389/fnhum.2012.00215

Kourtis, D., Sebanz, N., and Knoblich, G. (2010). Favouritism in the motor system: social interaction modulate action simulation. Biol. Lett. 6, 758-761. doi: $10.1098 /$ rsbl.2010.0478

Krach, S., Hegel, F., Wrede, B., Sagerer, G., Binkofski, F., and Kircher, T. (2008). Can machines think? Interaction and perspective taking with robots investigated via fMRI. PLoS ONE 3:e2597. doi:10.1371/journal.pone.0002597

Krämer, N. C. (2008). "Nonverbal communication," in Human Behavior in Military Contexts, eds J. Blascovich and C. R. Hartel (Washington, DC: The National Academies Press), 150-188.

Krumhuber, E., and Kappas, A. (2005). Moving smiles: the role of dynamic components for the perception of the genuineness of smiles. J. Nonverbal Behav. 29, 3-24. doi:10.1007/s10919-004-0887-x

Krumhuber, E., Manstead, A., and Kappas, A. (2007). Temporal aspects of facial displays in person and expression perception: the effects of smile dynamics, headtilt, and gender. J. Nonverbal Behav. 31, 39-56. doi:10.1007/s10919-006-0019-x

Kuzmanovic, B., Bente, G., Von Cramon, D. Y., Schilbach, L., Tittgemeyer, M., and Vogeley, K. (2012). Imaging first impressions: distinct neural processing of verbal and nonverbal social information. Neuroimage 60, 179-188. doi:10.1016/j.neuroimage.2011.12.046

Kuzmanovic, B., Georgescu, A. L., Eickhoff, S. B., Shah, N. J., Bente, G., Fink, G. R., et al. (2009). Duration matters: dissociating neural correlates of detection and evaluation of social gaze. Neuroimage 46, 1154-1163. doi:10.1016/j.neuroimage. 2009.03.037

Kuzmanovic, B., Schilbach, L., Georgescu, A. L., Kockler, H., Santos, N. S., Shah, N. J., et al. (2014). Dissociating animacy processing in high-functioning autism: neural correlates of stimulus properties and subjective ratings. Soc. Neurosci. 9, 309-325. doi:10.1080/17470919.2014.886618

Kuzmanovic, B., Schilbach, L., Lehnhardt, F.-G., Bente, G., and Vogeley, K. (2011). A matter of words: impact of verbal and nonverbal information on impression formation in high-functioning autism. Res. Autism Spectr. Disord. 5, 604-613. doi:10.1016/j.rasd.2010.07.005

Kylliäinen, A., and Hietanen, J. K. (2004). Attention orienting by another's gaze direction in children with autism. J. Child Psychol. Psychiatry 45, 435-444. doi:10.1111/j.1469-7610.2004.00235.x

Lachat, F., Hugueville, L., Lemaréchal, J.-D., Conty, L., and George, N. (2012). Oscillatory brain correlates of live joint attention: a dual-EEG study. Front. Hum. Neurosci. 6:156. doi:10.3389/fnhum.2012.00156

Lahiri, U., Trewyn, A., Warren, Z., and Sarkar, N. (2011a). Dynamic eye gaze and its potential in virtual reality based applications for children with autism spectrum disorders. Autism Open Access 1.

Lahiri, U., Warren, Z., and Sarkar, N. (2011b). Design of a gaze-sensitive virtual social interactive system for children with autism. IEEE Trans. Neural Syst. Rehabil. Eng. 19, 443-452. doi:10.1109/TNSRE.2011.2153874

LaViola, J. J. Jr. (2000). A discussion of cybersickness in virtual environments. SIGCHI Bull. 32, 47-56. doi:10.1145/333329.333344

Liepelt, R., and Brass, M. (2010). Top-down modulation of motor priming by belief about animacy. Exp. Psychol. 57, 221-227. doi:10.1027/1618-3169/a000028

Mar, R. A., Kelley, W. M., Heatherton, T. F., and Macrae, C. N. (2007). Detecting agency from the biological motion of veridical vs animated agents. Soc. Cogn. Affect. Neurosci. 2, 199-205. doi:10.1093/scan/nsm011

McDonnell, R., Jörg, S., McHugh, J., Newell, F., and O’Sullivan, C. (2008). "Evaluating the emotional content of human motions on real and virtual characters," in Proceedings of the 5th Symposium on Applied Perception in Graphics and Visualization APGV'08 (New York, NY: ACM Press), 67-74.

Menzies, R. (2011). Developing for Autism with User-Centred Design (ACM Press), 313. Available at: http://discovery.dundee.ac.uk/portal/en/research/developingfor-autism-with-usercentred-design(4eb135af-29f4-4be6-a99b-ee2e64b741dc). html

Millen, L., Cobb, S., and Patel, H. (2011). Participatory design approach with children with autism. Int. J. Disabil. Hum. Dev. 10, 289-294.

Minshew, N. J., and Goldstein, G. (1998). Autism as a disorder of complex information processing. Ment. Retard. Dev. Disabil. Res. Rev. 4, 129-136. doi:10.1002/ (SICI)1098-2779(1998)4:2<129::AID-MRDD10>3.0.CO;2-X

Mitchell, P., Parsons, S., and Leonard, A. (2007). Using virtual environments for teaching social understanding to 6 adolescents with autistic spectrum disorders. J. Autism Dev. Disord. 37, 589-600. doi:10.1007/s10803-006-0189-8 
Montague, P. R., Berns, G. S., Cohen, J. D., McClure, S. M., Pagnoni, G., Dhamala, M., et al. (2002). Hyperscanning: simultaneous fMRI during linked social interactions. Neuroimage 16, 1159-1164. doi:10.1006/nimg.2002.1150

Moore, D., Cheng, Y., McGrath, P., and Powell, N. J. (2005). Collaborative virtual environment technology for people with autism. Focus Autism Other Dev. Disabl. 20, 231-243. doi:10.1177/10883576050200040501

Moran, G., Dumas, J. E., and Symons, D. K. (1992). Approaches to sequential analysis and the description of contingency in behavioral interaction. Behav. Assess. $14,65-92$.

Mori, M. (1970). The uncanny valley. Energy 7, 33-35; translation by MacDorman, K. F., Minato, T.

Moser, E., Derntl, B., Robinson, S., Fink, B., Gur, R. C., and Grammer, K. (2007). Amygdala activation at $3 \mathrm{~T}$ in response to human and avatar facial expressions of emotions. J. Neurosci. Methods 161, 126-133. doi:10.1016/j.jneumeth. 2006.10.016

Mraz, R., Hong, J., Quintin, G., Staines, W. R., McIlroy, W. E., Zakzanis, K. K., et al. (2003). A platform for combining virtual reality experiments with functional magnetic resonance imaging. Cyberpsychol. Behav. 6, 359-368. doi:10. 1089/109493103322278736

Nakano, T., Tanaka, K., Endo, Y., Yamane, Y., Yamamoto, T., Nakano, Y., et al. (2010). Atypical gaze patterns in children and adults with autism spectrum disorders dissociated from developmental changes in gaze behaviour. Proc. Biol. Sci. 277, 2935-2943. doi:10.1098/rspb.2010.0587

Nass, C., and Moon, Y. (2000). Machines and mindlessness: social responses to computers. J. Soc. Issues 56, 81-103. doi:10.1111/0022-4537.00153

Nowak, K. L., and Biocca, F. (2003). The effect of the agency and anthropomorphism on users' sense of telepresence, copresence, and social presence in virtual environments. Presence (Camb.) 12, 481-494. doi:10.1162/105474603322761289

Park, S., and Catrambone, R. (2007). Social facilitation effects of virtual humans. Hum. Factors 49, 1054-1060. doi:10.1518/001872007X249910

Parsons, S., and Cobb, S. (2011). State-of-the-art of virtual reality technologies for children on the autism spectrum. Eur. J. Spec. Needs Educ. 26, 355-366. doi:10.1080/08856257.2011.593831

Parsons, S., and Cobb, S. (2013). "Who chooses what I need? Child voice and user-involvement in the development of learning technologies for children with autism," in EPSRC Observatory for Responsible Innovation in ICT. Available at: http://torrii.responsible-innovation.org.uk/resource-detail/1445

Parsons, S., Leonard, A., and Mitchell, P. (2006). Virtual environments for social skills training: comments from two adolescents with autistic spectrum disorder. Comput. Educ. 47, 186-206. doi:10.1016/j.compedu.2004.10.003

Parsons, S., and Mitchell, P. (2002). The potential of virtual reality in social skills training for people with autistic spectrum disorders. J. Intellect. Disabil. Res. 46, 430-443. doi:10.1046/j.1365-2788.2002.00425.x

Patterson, M. L. (1994). Interaction behavior and person perception: an integrative approach. Small Group Res. 2, 172-188. doi:10.1177/1046496494252002

Pelphrey, K. A., Morris, J. P., and McCarthy, G. (2005). Neural basis of eye gaze processing deficits in autism. Brain 128, 1038-1048. doi:10.1093/brain/ awh404

Pelphrey, K. A., Sasson, N. J., Reznick, J. S., Paul, G., Goldman, B. D., and Piven, J. (2002). Visual scanning of faces in autism. J. Autism Dev. Disord. 32, 249-261. doi:10.1023/A:1016374617369

Perani, D., Fazio, F., Borghese, N. A., Tettamanti, M., Ferrari, S., Decety, J., and Gilardi, M. C. (2001). Different brain correlates for watching real and virtual hand actions. Neuroimage 14, 749-758. doi:10.1006/nimg.2001.0872

Pfeiffer, U. J., Timmermans, B., Bente, G., Vogeley, K., and Schilbach, L. (2011). A non-verbal turing test: differentiating mind from machine in gaze-based social interaction. PLoS ONE 6, e27591. doi:10.1371/journal.pone.0027591

Pfeiffer, U. J., Timmermans, B., Vogeley, K., Frith, C. D., and Schilbach, L. (2013a). Towards a neuroscience of social interaction. Front. Hum. Neurosci. 7. 22. doi:10.3389/fnhum.2013.00022

Pfeiffer, U. J., Vogeley, K., and Schilbach, L. (2013b). From gaze cueing to dual eyetracking: novel approaches to investigate the neural correlates of gaze in social interaction. Neurosci. Biobehav. Rev. 37, 2516-2528. doi:10.1016/j.neubiorev. 2013.07.017

Piggot, J., Kwon, H., Mobbs, D., Blasey, C., Lotspeich, L., Menon, V., Bookheimer, S., and Reiss, A. L. (2004). Emotional attribution in high-functioning individuals with autistic spectrum disorder: a functional imaging study. J. Am. Acad. Child Adolesc. Psychiatry 43, 473-480. doi:10.1097/00004583-20040400000014
Pitskel, N. B., Bolling, D. Z., Hudac, C. M., Lantz, S. D., Minshew, N. J., Vander Wyk, B. C., and Pelphrey, K. A. (2011). Brain mechanisms for processing direct and averted gaze in individuals with autism. J. Autism Dev. Disord. 41, 1686-1693. doi:10.1007/s10803-011-1197-x

Porayska-Pomsta, K., Frauenberger, C., Pain, H., Rajendran, G., Smith, T., Menzies, R., Foster, M. E., Alcorn, A., Wass, S., Bernadini, S., et al. (2012). Developing technology for autism: an interdisciplinary approach. Pers. Ubiquitous Comput. 16, 117-127. doi:10.1007/s00779-011-0384-2

Poyatos, F. (1983). New Perspectives in Nonverbal Communication: Studies in Cultural Anthropology, Social Psychology, Linguistics, Literature, and Semiotics. Oxford: Pergamon Press.

Press, C., Gillmeister, H., and Heyes, C. (2006). Bottom-up, not top-down, modulation of imitation by human and robotic models. Eur. J. Neurosci. 24, 2415-2419. doi:10.1111/j.1460-9568.2006.05115.x

Press, C., Gillmeister, H., and Heyes, C. (2007). Sensorimotor experience enhances automatic imitation of robotic action. Proc. Biol. Sci. 274, 2509-2514. doi:10. 1098/rspb.2007.0774

Provost, M. P., Quinsey, V. L., and Troje, N. F. (2008). Differences in gait across the menstrual cycle and their attractiveness to men. Arch. Sex. Behav. 37, 598-604. doi:10.1007/s10508-007-9219-7

Przyrembel, M., Smallwood, J., Pauen, M., Singer, T (2012). Illuminating the dark matter of social neuroscience: considering the problem of social interaction from philosophical, psychological, and neuroscientific perspectives. Front. Hum. Neurosci. 6:190 doi:10.3389/fnhum.2012.00190

Putnam, C., and Chong, L. (2008). "Software and technologies designed for people with autism," in Proceedings of the 10th Annual ACM Conference on Computers and Accessibility ASSETS (Nova Scotia: Halifax), 3-10.

Redcay, E., Dodell-Feder, D., Mavros, P. L., Kleiner, M., Pearrow, M. J., Triantafyllou, C., et al. (2012). Atypical brain activation patterns during a face-to-face joint attention game in adults with autism spectrum disorder. Hum. Brain Mapp. 34, 2511-2523. doi:10.1002/hbm.22086

Redcay, E., Dodell-Feder, D., Pearrow, M. J., Mavros, P. L., Kleiner, M., Gabrieli, J. D. E., et al. (2010). Live face-to-face interaction during fMRI: a new tool for social cognitive neuroscience. Neuroimage 50, 1639-1647. doi:10.1016/j.neuroimage. 2010.01.052

Riby, D. M., and Doherty, M. J. (2009). Tracking eye movements proves informative for the study of gaze direction detection in autism. Res. Autism Spectr. Disord. 3, 723-733. doi:10.1016/j.rasd.2009.02.001

Rizzo, A. S., and Kim, G. J. (2005). A SWOT analysis of the field of virtual reality rehabilitation and therapy. Presence (Camb.) 14, 119-146. doi:10.1162/ 1054746053967094

Rutherford, M. D., and Towns, A. M. (2008). Scan path differences and similarities during emotion perception in those with and without autism spectrum disorders. J. Autism Dev. Disord. 38, 1371-1381. doi:10.1007/s10803-007-0525-7

Rutten, A., Cobb, S., Neale, H., Kerr, S., Leonard, A., Parsons, S., et al. (2003). The AS interactive project: single-user and collaborative virtual environments for people with high-functioning autistic spectrum disorders. J. Vis. Comput. Animat. 14, 233-241. doi:10.1002/vis.320

Saito, D. N., Tanabe, H. C., Izuma, K., Hayashi, M. J., Morito, Y., Komeda, H., et al. (2010). "Stay tuned": inter-individual neural synchronization during mutual gaze and joint attention. Front. Integr. Neurosci. 4:127. doi:10.3389/fnint.2010. 00127

Santos, P., Gierlinger, T., Stork, A., and Mcintyre, D. (2007). "Display and rendering technologies for virtual and mixed reality design review," in 7th International Conference on Construction Applications of Virtual Reality (Pennsylvania: CONVR), 165-175.

Sartori, L., Becchio, C., Bara, B. G., and Castiello, U. (2009). Does the intention to communicate affect action kinematics? Conscious. Cogn. 18, 766-772. doi:10.1016/j.concog.2009.06.004

Saygin, A. P., Chaminade, T., Ishiguro, H., Driver, J., and Frith, C. (2011). The thing that should not be: predictive coding and the uncanny valley in perceiving human and humanoid robot actions. Soc. Cogn. Affect. Neurosci. 7, 413-422. doi:10.1093/scan/nsr025

Schilbach, L. (2014). On the relationship of online and offline social cognition. Front. Hum. Neurosci. 8:278. doi:10.3389/fnhum.2014.00278

Schilbach, L., Eickhoff, S. B., Cieslik, E. C., Kuzmanovic, B., and Vogeley, K. (2012). Shall we do this together? Social gaze influences action control in a comparison group, but not in individuals with high-functioning autism. Autism 16, 151-162. doi: $10.1177 / 1362361311409258$ 
Schilbach, L., Timmermans, B., Reddy, V., Costall, A., Bente, G., Schlicht, T., et al. (2013). Toward a second-person neuroscience. Behav. Brain Sci. 36, 393-414. doi:10.1017/S0140525X12002452

Schilbach, L., Wilms, M., Eickhoff, S. B., Romanzetti, S., Tepest, R., Bente, G., et al. (2010). Minds made for sharing: initiating joint attention recruits reward-related neurocircuitry. J. Cogn. Neurosci. 22, 2702-2715. doi:10.1162/jocn.2009.21401

Schilbach, L., Wohlschlaeger, A. M., Kraemer, N. C., Newen, A., Shah, N. J., Fink, G. R., et al. (2006). Being with virtual others: neural correlates of social interaction. Neuropsychologia 44, 718-730. doi:10.1016/j.neuropsychologia.2005.07.017

Schroeder, R. (2002). "Social Interaction in virtual environments: key issues, common themes, and a framework for research," in The Social Life of Avatars, ed. R. Schroeder (New York, NY: Springer-Verlag), 1-18.

Schulte-Rüther, M., Greimel, E., Markowitsch, H. J., Kamp-Becker, I., Remschmidt, H., Fink, G. R., et al. (2011). Dysfunctions in brain networks supporting empathy: an fMRI study in adults with autism spectrum disorders. Soc. Neurosci. 6, 1-21. doi:10.1080/17470911003708032

Schwartz, C., Bente, G., Gawronski, A., Schilbach, L., and Vogeley, K. (2010). Responses to nonverbal behaviour of dynamic virtual characters in highfunctioning autism. J. Autism Dev. Disord. 40, 100-111. doi:10.1007/s10803009-0843-z

Self, T., Scudder, R. R., Weheba, G., and Crumrine, D. (2007). A virtual approach to teaching safety skills to children with autism spectrum disorder. Top. Lang. Disord. 27, 242. doi:10.1097/01.TLD.0000285358.33545.79

Senju, A., Hasegawa, T., and Tojo, Y. (2005). Does perceived direct gaze boost detection in adults and children with and without autism? The stare-in-the-crowd effect revisited. Vis. Cogn. 12, 1474-1496. doi:10.1080/13506280444000797

Senju, A., and Johnson, M. H. (2009). The eye contact effect: mechanisms and development. Trends Cogn. Sci. (Regul. Ed.) 13, 127-134. doi:10.1016/j.tics.2008. 11.009

Senju, A., Kikuchi, Y., Hasegawa, T., Tojo, Y., and Osanai, H. (2008). Is anyone looking at me? Direct gaze detection in children with and without autism. Brain Cogn. 67, 127-139. doi:10.1016/j.bandc.2007.12.001

Sharples, S., Cobb, S., Moody, A., and Wilson, J. R. (2008). Virtual reality induced symptoms and effects (VRISE): comparison of head mounted display (HMD), desktop and projection display systems. Displays 29, 58-69. doi:10.1016/j.displa. 2007.09.005

Shimada, S. (2010). Deactivation in the sensorimotor area during observation of a human agent performing robotic actions. Brain Cogn. 72, 394-399. doi:10.1016/j.bandc.2009.11.005

Sproull, L., Subramani, M., Kiesler, S., Walker, J. H., and Waters, K. (1996). When the interface is a face. Hum. Comput. Interact. 11, 97-124. doi:10.1207/ s15327051hcil102_1

Stanley, J., Gowen, E., and Miall, R. C. (2007). Effects of agency on movement interference during observation of a moving dot stimulus. J. Exp. Psychol. Hum. Percept. Perform. 33, 915-926. doi:10.1037/0096-1523.33.4.915

Stanley, J., Gowen, E., and Miall, R. C. (2010). How instructions modify perception: an fMRI study investigating brain areas involved in attributing human agency. Neuroimage 52, 389-400. doi:10.1016/j.neuroimage.2010.04.025

Strickland, D. (1997). Virtual reality for the treatment of autism. Stud. Health Technol. Inform. 44, 81-86.

Tanabe, H. C., Kosaka, H., Saito, D. N., Koike, T., Hayashi, M. J., Izuma, K., et al. (2012). Hard to "tune in": neural mechanisms of live face-to-face interaction with high-functioning autistic spectrum disorder. Front. Hum. Neurosci. 6:268. doi:10.3389/fnhum.2012.00268

Trevarthen, C., and Daniel, S. (2005). Disorganized rhythm and synchrony: early signs of autism and Rett syndrome. Brain Dev. 27(Suppl. 1), S25-S34. doi:10.1016/j.braindev.2005.03.016

Uljarevic, M., and Hamilton, A. (2013). Recognition of emotions in autism: a formal meta-analysis. J. Autism Dev. Disord. 43, 1517-1526. doi:10.1007/s10803012-1695-5

Van Overwalle, F., and Baetens, K. (2009). Understanding others' actions and goals by mirror and mentalizing systems: a meta-analysis. Neuroimage 48, 564-584. doi:10.1016/j.neuroimage.2009.06.009

Villarreal, M., Fridman, E. A., Amengual, A., Falasco, G., Gerschcovich, E. R., Gerscovich, E. R., et al. (2008). The neural substrate of gesture recognition. Neuropsychologia 46, 2371-2382. doi:10.1016/j.neuropsychologia.2008.03.004
Vogeley, K., and Bente, G. (2010). "Artificial humans": psychology and neuroscience perspectives on embodiment and nonverbal communication. Neural Netw. 23, 1077-1090. doi:10.1016/j.neunet.2010.06.003

von der Pütten, A. M., Krämer, N. C., and Gratch, J. (2010a). “How our personality shapes our interactions with virtual characters - implications for research and development," in Intelligent Virtual Agents Lecture Notes in Computer Science, eds J. Allbeck, N. Badler, T. Bickmore, C. Pelachaud, and A. Safonova (Berlin: Springer), 208-221.

von der Pütten, A. M., Krämer, N. C., Gratch, J., and Kang, S. (2010b). It doesn't matter what you are! - Explaining social effects of agents and avatars. Comput. Hum. Behav. 26, 1641-1650. doi:10.1016/j.chb.2010.06.012

Wallace, S., Parsons, S., Westbury, A., White, K., White, K., and Bailey, A. (2010). Sense of presence and atypical social judgments in immersive virtual environments. Responses of adolescents with autism spectrum disorders. Autism 14, 199-213. doi:10.1177/1362361310363283

Walsh, J. A., Vida, M. D., and Rutherford, M. D. (2014). Strategies for perceiving facial expressions in adults with autism spectrum disorder. J. Autism Dev. Disord. 44, 1018-1026. doi:10.1007/s10803-013-1953-1

Wang, A. T., Lee, S. S., Sigman, M., and Dapretto, M. (2007). Reading affect in the face and voice: neural correlates of interpreting communicative intent in children and adolescents with autism spectrum disorders. Arch. Gen. Psychiatry 64, 698-708. doi:10.1001/archpsyc.64.6.698

Wang, M., and Reid, D. (2011). Virtual reality in pediatric neurorehabilitation: attention deficit hyperactivity disorder, autism and cerebral palsy. Neuroepidemiology 36, 2-18. doi:10.1159/000320847

Wang, Y., and Hamilton, A. F. (2012). Social top-down response modulation (STORM): a model of the control of mimicry in social interaction. Front. Hum. Neurosci. 6:153. doi:10.3389/fnhum.2012.00153

Wang, Y., Ramsey, R., Hamilton, A. F., and de, C. (2011). The control of mimicry by eye contact is mediated by medial prefrontal cortex. J. Neurosci. 31, 12001-12010. doi:10.1523/JNEUROSCI.0845-11.2011

Ware, C., Arthur, K., and Booth, K. S. (1993). "Fish Tank Virtual Reality," in Proceedings of the INTERACT '93 and CHI '93 Conference on Human Factors in Computing Systems CHI '93 (New York, NY: ACM Press), 37-42.

Willis, J., and Todorov, A. (2006). First impressions: making up your mind after a 100-ms exposure to a face. Psychol. Sci. 17, 592-598. doi:10.1111/j.1467-9280. 2006.01750.x

Wilms, M., Schilbach, L., Pfeiffer, U., Bente, G., Fink, G. R., and Vogeley, K. (2010). It's in your eyes - using gaze-contingent stimuli to create truly interactive paradigms for social cognitive and affective neuroscience. Soc. Cogn. Affect. Neurosci. 5, 98-107. doi:10.1093/scan/nsq024

World Health Organization. (1993). ICD-10. The International Classification of Disease-Revision 10. Classification of Mental and Behavioral Disorders: Diagnostic Criteria for Research. Geneva: World Health Organization.

Yee, N., Bailenson, J. N., Urbanek, M., Chang, F., and Merget, D. (2007). The unbearable likeness of being digital: the persistence of nonverbal social norms in online virtual environments. Cyberpsychol. Behav. 10, 115-121. doi:10.1089/ cpb.2006.9984

Conflict of Interest Statement: The authors declare that the research was conducted in the absence of any commercial or financial relationships that could be construed as a potential conflict of interest.

Received: 06 June 2014; accepted: 22 September 2014; published online: 15 October 2014.

Citation: Georgescu AL, Kuzmanovic B, Roth D, Bente G and Vogeley K(2014) The use of virtual characters to assess and train non-verbal communication in high-functioning autism. Front. Hum. Neurosci. 8:807. doi: 10.3389/fnhum.2014.00807 This article was submitted to the journal Frontiers in Human Neuroscience.

Copyright (c) 2014 Georgescu, Kuzmanovic, Roth, Bente and Vogeley. This is an openaccess article distributed under the terms of the Creative Commons Attribution License (CC BY). The use, distribution or reproduction in other forums is permitted, provided the original author(s) or licensor are credited and that the original publication in this journal is cited, in accordance with accepted academic practice. No use, distribution or reproduction is permitted which does not comply with these terms. 